SANDIA REPORT

SAND95-1324 - UC-610

Unlimited Release

Printed July 1995

TiECELEC

ม⿰日月⿺ $18 \mathrm{Ms}$

OSTI

\title{
User's Guide for the KBERT 1.0 Code
}

\section{For the Knowledge-Based Estimation of Hazards of Radioactive Material Releases from DOE Nuclear Facilities}

D. S. Browitt, K. E. Washington, D. A. Powers, D. K. Monroe, T. J. Heames

Prepared by

Sandia National Laboratories

Albuquerque, New Mexico 87185 and Livermore, California 94550

for the United States Department of Energy

under Contract DE-AC04-94ALB5000

Approved for public release; distribution is unlimited.
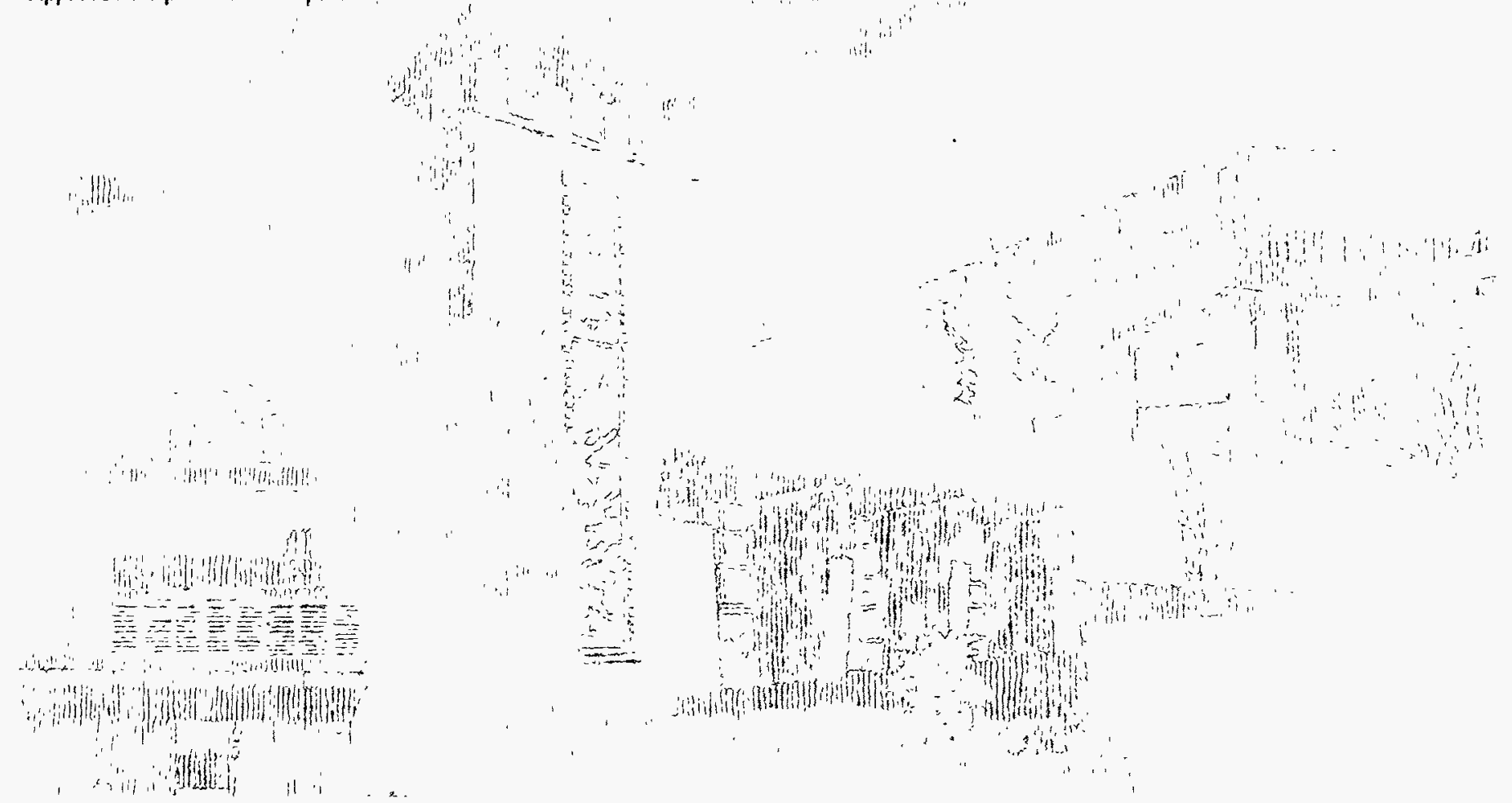
Issued by Sandia National Laboratories, operated for the United States Department of Energy by Sandia Corporation.

NOTICE: This report was prepared as an account of work sponsored by an agency of the United States Government. Neither the United States Government nor any agency thereof, nor any of their employees, nor any of their contractors, subcontractors, or their employees, makes any warranty, express or implied, or assumes any legal liability or responsibility for the accuracy, completeness, or usefulness of any information, apparatus, product, or process disclosed, or represents that its use would not infringe privately owned rights. Reference herein to any specific commercial product, process, or service by trade name, trademark, manufacturer, or otherwise, does not necessarily constitute or imply its endorsement, recommendation, or favoring by the United States Government, any agency thereof or any of their contractors or subcontractors. The views and opinions expressed herein do not necessarily state or reflect those of the United States Government, any agency thereof or any of their contractors.

Printed in the United States of America. This report has been reproduced directly from the best available copy.

Available to DOE and DOE contractors from Office of Scientific and Technical Information

PO Box 62

Oak Ridge, TN 37831

Prices available from (615) 576-8401, FTS 626-8401

Available to the public from

National Technical Information Service

US Department of Commerce

5285 Port Royal Rd

Springfield, VA 22161

NTIS price codes

Printed copy: A03

Microfiche copy: A01 


\section{DISCLAIMER}

Portions of this document may be illegible in electronic image products. Images are produced from the best available original document. 
SAND95-1324

Category UC-610

Unlimited Release

Printed July 1995

\title{
User's Guide for the KBERT 1.0 Code
}

\author{
for the Knowledge-Based Estimation of Hazards of Radioactive Material \\ Releases from DOE Nuclear Facilities
}

\author{
D. S. Browitt, K. E. Washington, \\ Information Systems Applications Department \\ D. A. Powers \\ Nuclear Facilities Safety Department \\ D. K. Monroe \\ Accident Analysis/Consequences Assessment Department \\ Sandia National Laboratories \\ Albuquerque, NM 87185-5800 \\ and T. J. Heames \\ Science Applications International Corporation \\ Albuquerque, NM 87102
}

\begin{abstract}
The possibility of worker exposure to radioactive materials during accidents at nuclear facilities is a principal concern of the DOE. The KBERT software has been developed at Sandia National Laboratories under DOE support to address this issue by assisting in the estimation of risks posed by accidents at chemical and nuclear facilities. KBERT is an acronym for Knowledge-Based system for Estimating hazards of Radioactive material release Transients. The current prototype version of KBERT focuses on calculation of doses and consequences to in-facility workers due to accidental releases of radioactivity. This report gives detailed instructions on how a user who is familiar with the design, layout and potential hazards of a facility can use KBERT to assess the risks to workers in that facility. KBERT is a tool that allows a user to simulate possible accidents and observe the predicted consequences. Potential applications of KBERT include the evaluation of the efficacy of evacuation practices, worker shielding, personal protection equipment and the containment of hazardous materials.
\end{abstract}




\section{Contents}

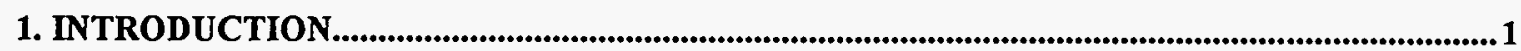

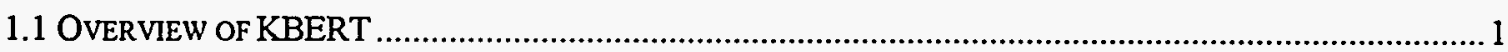

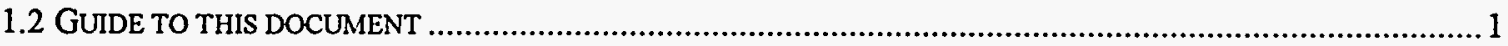

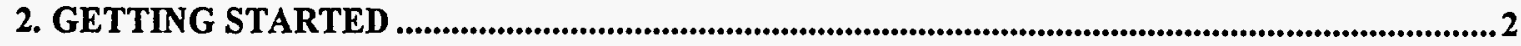

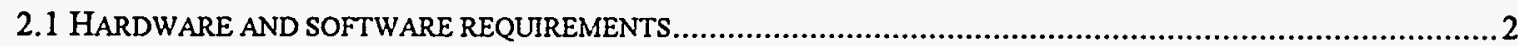

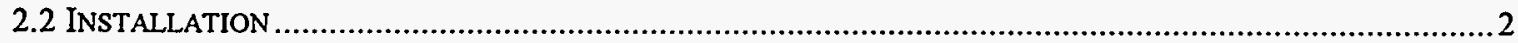

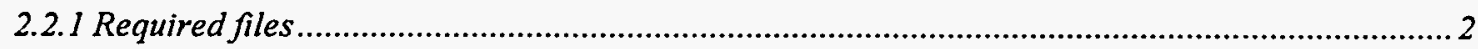

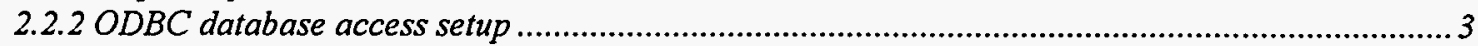

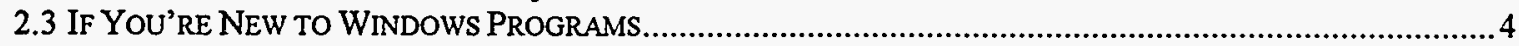

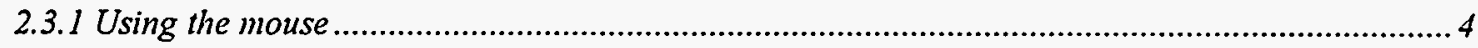

2.3.2 Using the menu

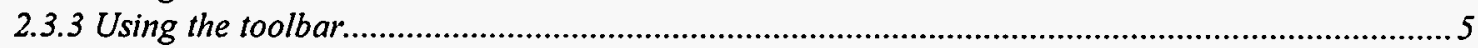

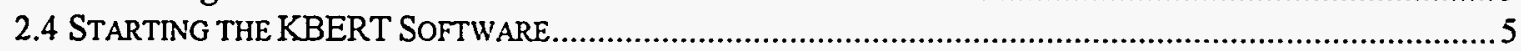

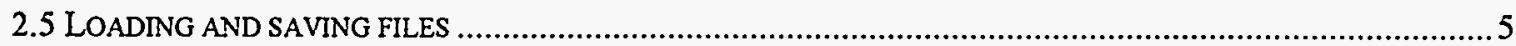

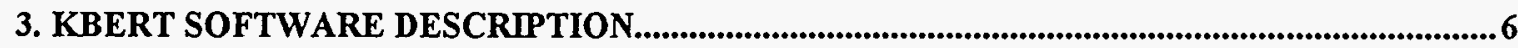

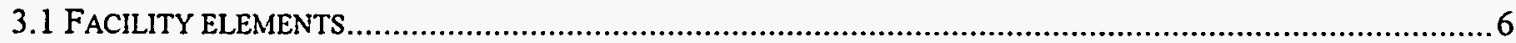

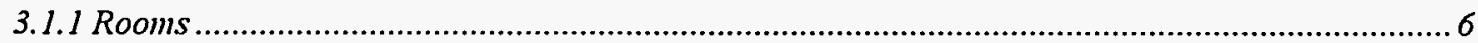

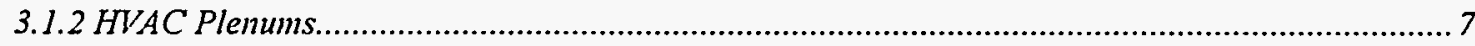

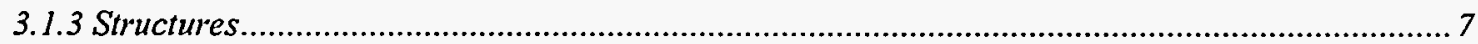

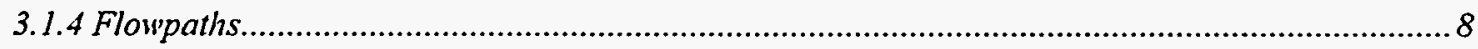

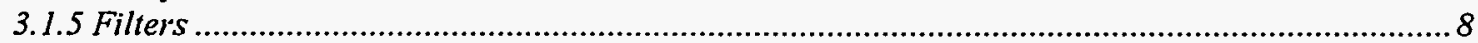

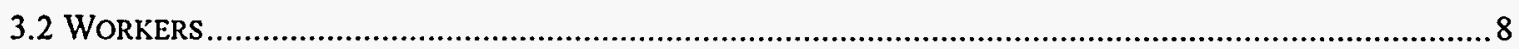

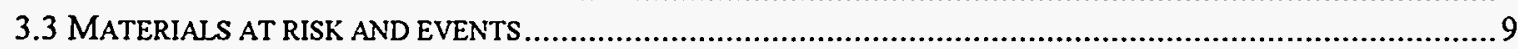

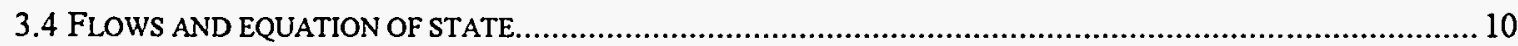

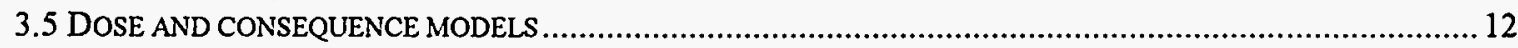

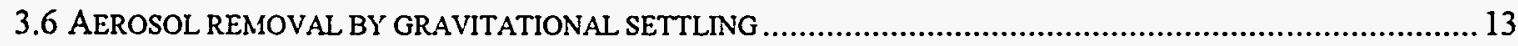

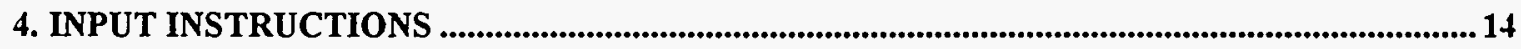

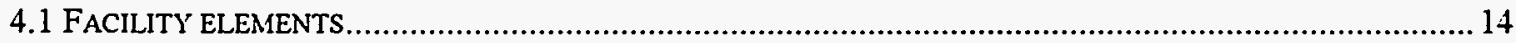

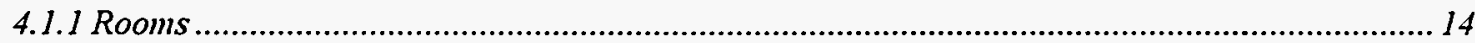

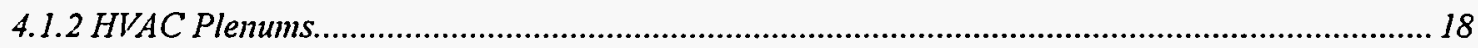

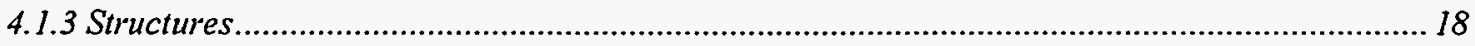

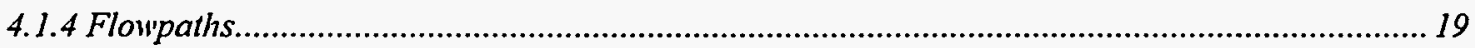

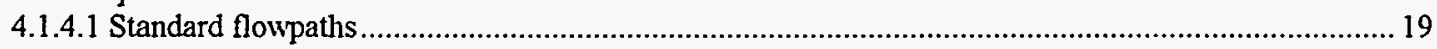

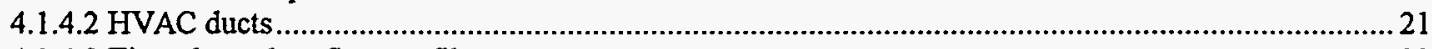

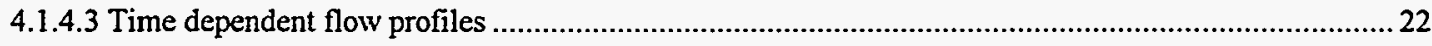

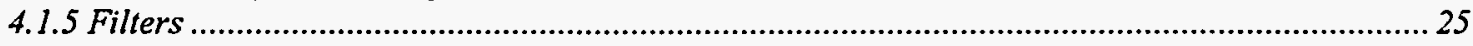

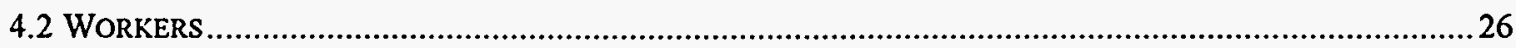

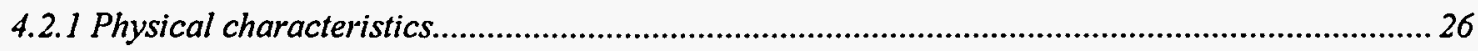

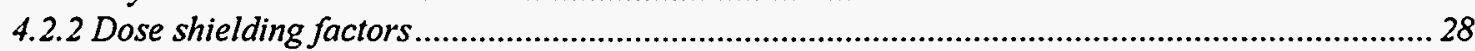

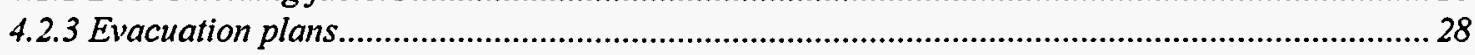

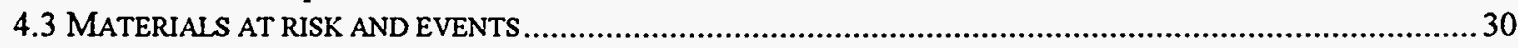

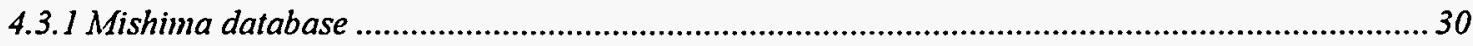

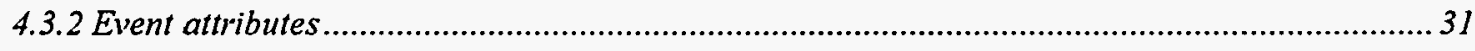

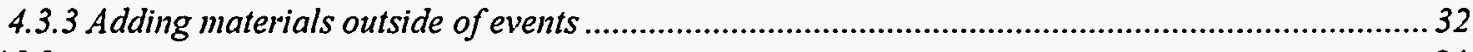

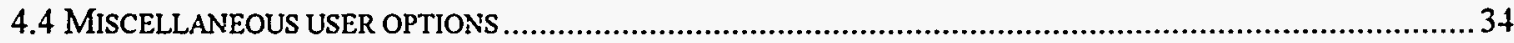




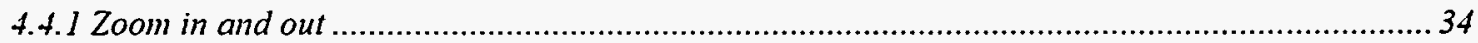

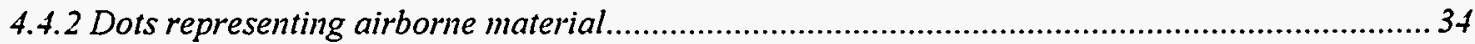

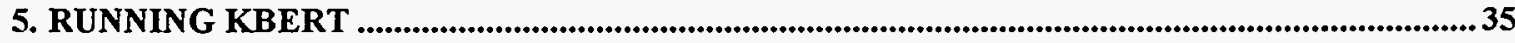

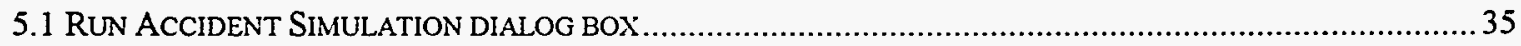

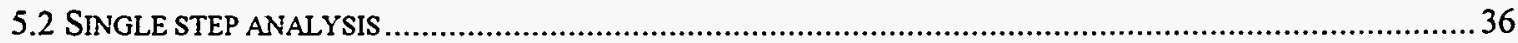

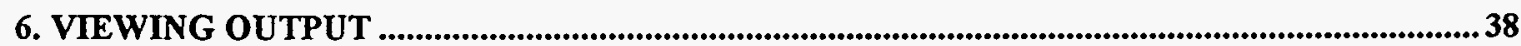

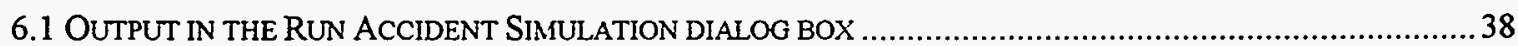

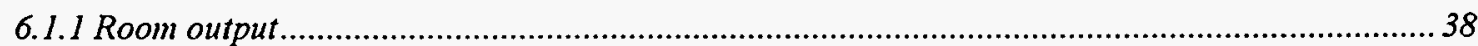

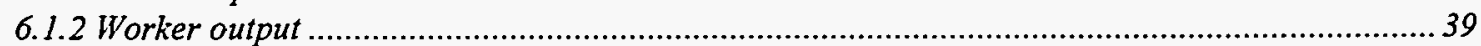

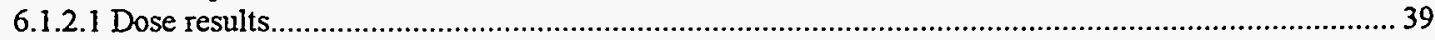

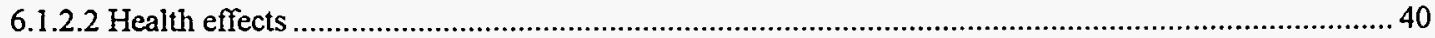

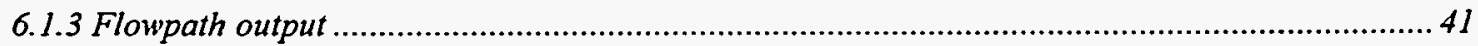

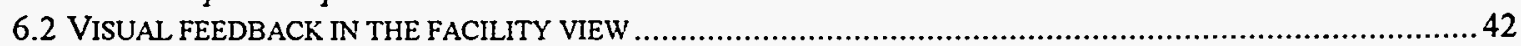

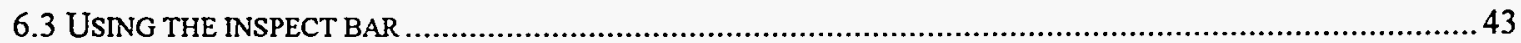

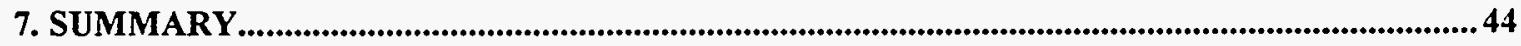

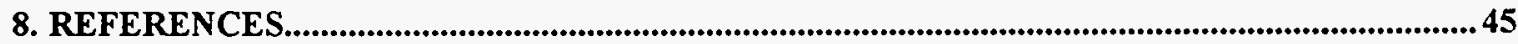




\section{KBERT User's Guide}

\section{Introduction}

Accident risks faced by workers at Department of Energy (DOE) facilities are receiving increased attention because of heightened awareness, aging of facilities, changing mission, and the advent of new activities (e.g., decontamination and decommissioning). The KBERT software is being developed at Sandia National Laboratories under DOE support to address these issues by assisting in the estimation of risks due to accidents at chemical and nuclear facilities. KBERT is an acronym for Knowledge-Based system for Estimating hazards of Radioactive material release Transients. The current prototype version of KBERT focuses on the calculation of doses and consequences to in-facility workers produced by accidental releases of radioactivity. This report describes the KBERT software and provides instructions for its use.

\subsection{Overview of KBERT}

The KBERT software can be used for qualitative or quantitative risk analyses, assessments of heating ventilation and air conditioning (HVAC) systems, the evaluation of alarm systems, and the assessment of evacuation plans. Facilities are modeled in KBERT as a number of rooms connected by hallways, HVAC ducts, and other flowpaths. The Mishima [1993] $]^{1}$ database on the amounts of material released to the atmosphere as a function of the accident and the respirable fractions of the released materials is incorporated in KBERT as an electronic relational database that KBERT accesses transparently to the user. There are also databases on material properties and health effects of radionuclide exposure in the software. KBERT uses mechanistic models of aerosol transport within a facility given user prescribed air flow rates. Filters that mitigate radionuclide exposures in an accident can be modeled in any flowpath. Worker movements in response to alarms can be modeled by specifying a detailed evacuation plan for each worker or group of workers. Dose models include the effects of inhalation, cloudshine, groundshine, and skin contamination. The effect of half or full mask personal protection equipment is modeled, including shine protection, and skin protection. Output from KBERT includes airborne and surface concentrations of hazardous material throughout the facility as well as whole-body and organ-specific doses to workers.

\subsection{Guide to this document}

Chapter 2 describes how to begin using KBERT, including installing the software on the computer where it will be used. This chapter also covers some basic information about using software under the Microsoft Windows operating system. If you already have KBERT installed and are an experienced Windows user, you should skip this chapter.

Chapter 3 briefly describes the models in KBERT that are used to calculate the release, transport, and removal of radioactive material in the facility. Additional leak path models as detailed by Heames and Brockmann $[1994]^{2}$ could be implemented within KBERT. The models used to calculate dose to in-facility workers are also briefly described; however, the reader is referred to Monroe's [1994] $]^{3}$ assessment for a detailed description 
of the dose models. Reading this section is not required to learn how to use KBERT; however, all users are encouraged to eventually read this section to gain an understanding of the modeling approach and key assumptions made.

Chapter 4 provides instructions for specifying input to KBERT. All required and optional inputs are described in this chapter, including instructions for defining the physical facility layout, workers in the facility, events and the materials at risk, and various options. The dialog boxes where most KBERT input is solicited are also shown and described in this chapter. Analysts planning to use KBERT will want to read this chapter in detail.

Chapter 5 describes how to run KBERT. Running KBERT once a facility has been defined is quite straightforward. Most experienced analysts, particularly those experienced in using software written for Microsoft Windows, will probably be able to run KBERT without referring to Chapter 5 . This chapter is therefore best treated as a reference or for when one wants to perform more advanced KBERT functions.

The last chapter, Chapter 6, describes how to obtain output from KBERT. The prototype version of KBERT only produces screen output. Like the input, the interpretation of KBERT output is rather obvious. One not so obvious output feature of KBERT is the inspect bar. Analysts should find this feature of KBERT invaluable for extracting key results from an analysis. The inspect bar is described in Chapter 6 along with a brief description of other output features of KBERT.

\section{Getting Started}

\subsection{Hardware and software requirements}

To use KBERT, you need:

- An IBM-compatible PC with an 80386 processor or higher, although a 486 or higher is highly recommended.

- Microsoft Windows 3.1 or higher.

- VGA graphics display (SVGA recommended).

- A mouse or compatible pointing device.

- A hard disk with at least $10 \mathrm{MB}$ of free space.

\subsection{Installation}

\subsubsection{Required files}

KBERT is distributed on two disks and is installed by first running the setup program on disk one and following the on-line instructions. After the setup procedure is complete, there is one more installation step that must be done manually. The next section describes this step in detail. This step is required and cannot be skipped. If this step is skipped, 
KBERT will not be able to access the electronic materials, health effects, and material release databases, and will abort when you try to run it.

\subsubsection{ODBC database access setup}

Before you can run KBERT for the first time, you must first update the ODBC catalog of stored procedures. Microsoft Open Database Connectivity (ODBC) is a $\mathrm{C}$ programming language interface for database connectivity. This will tell the KBERT application where to find the database it needs to run. This can be done by initiating the "ODBC Administrator" from the KBERT Application Window that will be created on your system when you install KBERT:

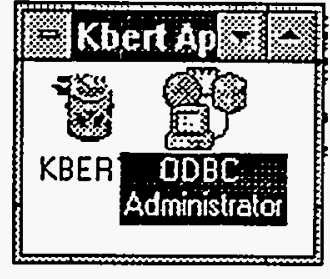

Double click on the icon to initiate the application.

The "Data Sources" screen should appear.

\section{的枯:}

Click on the "Add" button to create the new catalog entry.

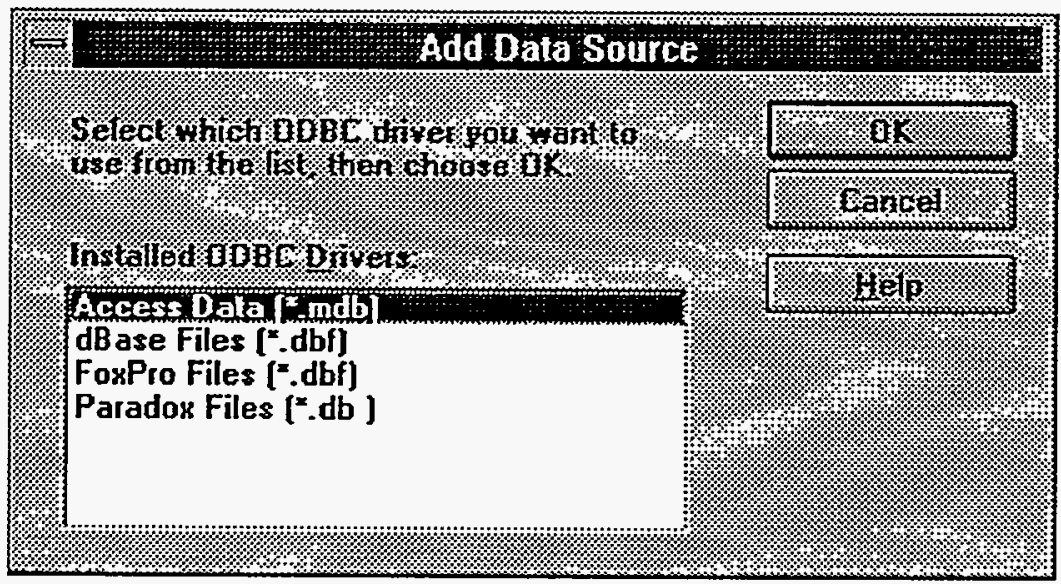

Highlight "Access Data" then click on "OK".

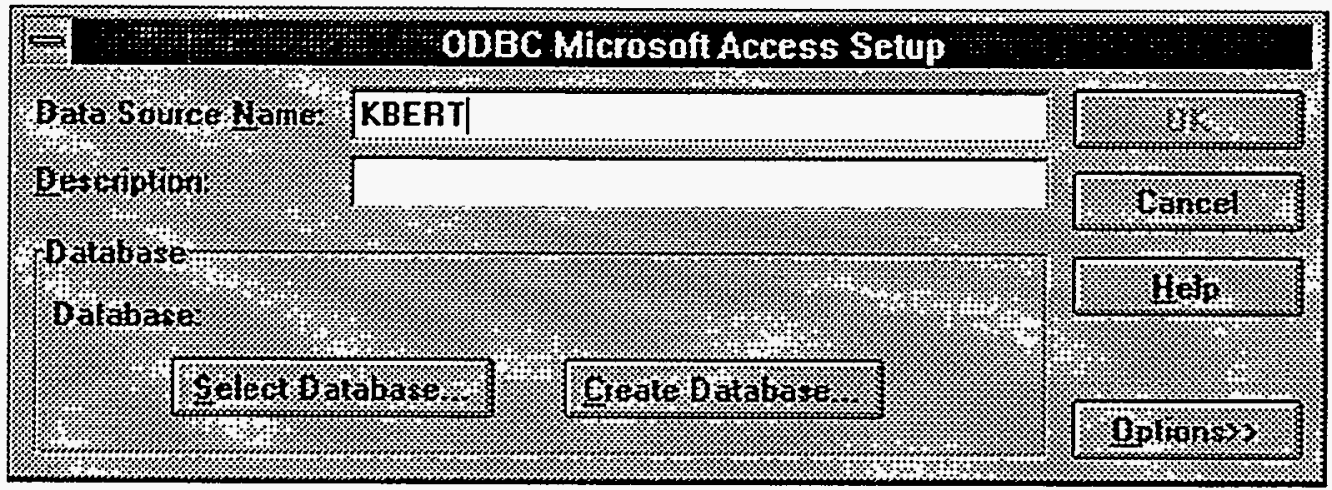

Enter "KBERT" for Data Source Name then click on "Select Database". 


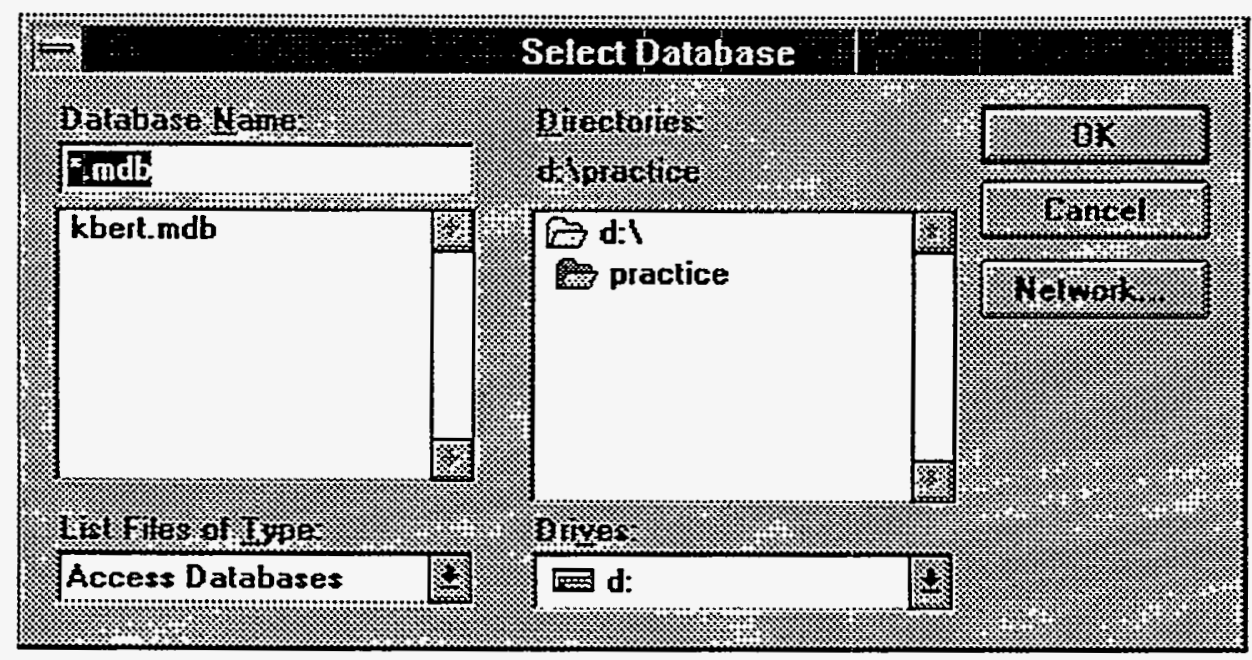

You must then locate the file named "KBERT.mdb" in the directory where you installed the software. Once you have found it and highlighted the file name, click on "OK".

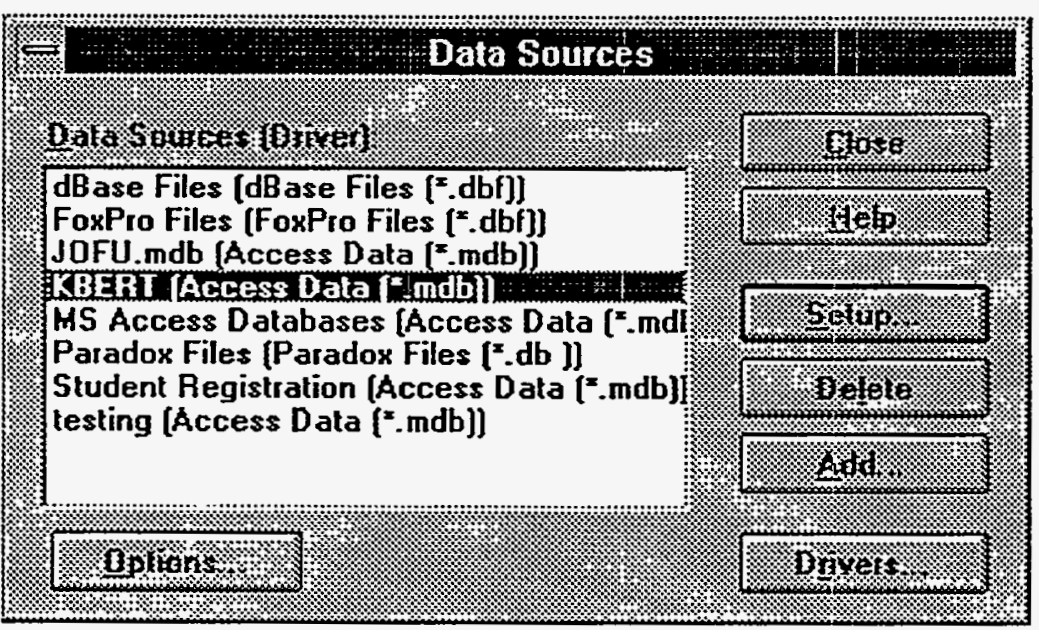

The highlighted line should now appear in your list of data sources. Click on "OK", close the "Data Sources" window, and you are now ready to run KBERT.

\subsection{If you're new to windows programs}

This section briefly reviews some basic features of KBERT that are common to most Windows programs If you are familiar with running other Windows applications then skip this section.

\subsubsection{Using the mouse}

The mouse is used to aid in input and output. Mastering its use is essential for effective use of KBERT. Items that may be selected with the mouse include menu choices, toolbar buttons, dialog box options, and KBERT facility modules on screen. To select an item with the mouse simply point to it and click the left mouse button. All KBERT facility modules on the main screen may be selected and then moved around on the screen except for the environment room. To move an item on the screen, point to it, press down the left 
mouse button and hold it, then move the mouse. When the item is in the desired location, release the left button. For more information about using the mouse under Windows, consult the Microsoft Windows manuals and on-line tutorial provided with the Windows operating system.

\subsubsection{Using the menu}

Essentially all features of KBERT can be accessed using the menu. To select a menu item point to one of the items shown and click the left mouse button. A sub-menu will appear beneath the selected item. The specific item desired should then be pointed to and the left mouse button clicked again. If the item has [...] after it, this will invoke a dialog box where more choices can be made. Otherwise, the selected function will execute immediately. For more information on menu usage, consult the Microsoft Windows manuals and tutorial.

\subsubsection{Using the toolbar}

The toolbar in KBERT is an optional feature that can be turned on or off using the View menu selection. If this feature is on, a row of small icons will be shown beneath the menu. These icons are simply shortcuts for selecting commonly used features on the menu. To use the shortcut, simply point to the item of choice and click the left mouse button. The first three buttons on the toolbar are file shortcuts. The scissors icon is a delete item shortcut, which will remove any selected modules from the facility. The next two are shortcuts for single step run and run reset. The next six are shortcuts for adding new objects to a facility. To find out which button does what, experiment on a sample file. The last toolbar button is for showing the program's "about" information box. This box shows information about the developers of KBERT.

\subsection{Starting the KBERT Software}

Once KBERT has been installed, running it is a simple matter of double-clicking on its icon. You can also run KBERT by double-clicking on its name from within File Manager, as with any other Windows application. Normally KBERT loads as a full screen application with a generic one room facility shown on the screen. Typically you use this simple facility as a starting point to create your own facilities, but you can delete the one room and/or the HVAC system and start from scratch. You can also load a facility from disk that you have created in a previous KBERT session as described in the following section. When the KBERT icon is set up, normally no parameters are given following its name. If instead you specify the name of a facility known to exist on your hard disk following the program name, that facility will automatically load when you double click on the KBERT icon.

\subsection{Loading and saving files}

In KBERT, all aspects of a user defined facility can be saved in a file. By default, KBERT files are given the ".fac" extension. You can override this to give your files any extension, but this is not recommended. Files may be saved by selecting the "Save" or "Save As" 
option under the File menu. Alternatively, you can click the save icon on the toolbar to save the current file. When files are saved, they are reset to time zero; therefore, analysis results are never saved to disk. This is unnecessary due to the short run times. To review the results of a given analysis, the file must be loaded and re-run.

Previously saved files may be loaded by selecting "Open" from the File menu. Only files saved by KBERT may be loaded into KBERT. Any attempt to open a file not saved by KBERT will produce an error message. If the open is successful, the facility previously saved will be shown on screen. All facilities loaded into KBERT from disk will be set to time zero, ready for you to start an analysis. The last four items on the File menu above the Exit selection lists the last four files loaded into KBERT. This can be used as a shortcut to quickly load any one of the last four files you have analyzed. Typically only files with the ".fac" extension are listed in the Load dialog box; however, files with other extensions can be listed by changing the selection under "List Files of Type:" on the Open dialog box.

\section{KBERT Software Description}

\subsection{Facility elements}

The KBERT software represents facilities as a collection of interconnected elements on the screen. The following elements are included: rooms, HVAC plenums, flowpaths, filters, and structures. All of these, except structures, are visible on the main KBERT screen. Although structures are not shown graphically, their attributes may be specified from within the room definition input box (more commonly called a dialog box). Filters are defined with the Flowpath dialog box. All other facility elements are defined from their own dialog box that is invoked by clicking on their screen symbol from the toolbar or via the insert menu item. Specifics about each facility element are discussed in the sections below.

\subsubsection{Rooms}

Rooms are the basic components used to describe a facility. A facility is described as one or more rooms interconnected by doorway flowpaths and/or HVAC ducts. A facility can have any number of rooms but must always have at least one, the environment room. The environment room is delimited by four layers of broken red lines that outline the facility drawing. The environment room represents the out of doors and is a source of fresh air and exhaust from the facility for ventilation systems. The environment is the only room where an event cannot take place. Each room can contain any number of workers, structures (floor, wall, and roof structures are used to define aerosol settling surface areas within a room), materials at risk, and events. Rooms are shown on screen as cyan colored squares. The height of the square is proportional to the user specified height of the room. The width of the square is proportional to the volume of the room divided by its height. With this approach, the size of the square shown on screen is directly proportional to the volume of the room it represents. The location of rooms on screen are under the control of the user (KBERT's layout does not represent a birds-eye view of the facility). As rooms are moved, the interconnections are automatically adjusted. Users are 
encouraged to move rooms around until a visually appealing arrangement (with few doorway lines crossing each other) is obtained. Room physical characteristics, including embedded structures, events, and physical size are specified in the Room dialog box. The Room dialog box is accessed either by double clicking on the box that represents the room of interest, or by double clicking on the room name of interest in the Run Accident Simulation dialog box. New rooms are added to a facility by selecting the "Room" option under the Insert menu or by selecting the button containing the cyan square in the toolbar.

\subsubsection{HVAC Plenums}

An HVAC plenum is a special type of room used to represent the common volume of an HVAC system. Plenums are distinguished from standard rooms on screen by their fixed size and purple color. Return and source vents in a given HVAC system connect to the same HVAC plenum. When a new facility is created one HVAC plenum is automatically included (each HVAC system has exactly one HVAC plenum). This initial HVAC system can be kept, deleted, or additional HVAC systems can be added at the user's discretion. Any number of plenums may be added to a given facility. Each new HVAC plenum represents a new separate HVAC system. Air and materials drawn from rooms into one HVAC plenum are not mixed with air and materials drawn from rooms into other HVAC plenums. The characteristics of HVAC plenums are defined using the same Room dialog box described in the previous section. Doorway flowpaths cannot be connected to HVAC plenum rooms, and workers and events are not allowed in HVAC plenum rooms. HVAC systems are added by selecting the "HVAC System" option under the Insert menu or by selecting the button containing the purple rectangle in the toolbar.

\subsubsection{Structures}

Structures are embedded within rooms and are used to define deposition surfaces for aerosols. There are three types of structures that can be included in a room: floors, walls, and roofs. Normally each room will contain one of each type; however, the user can delete or add new structures prior to starting a run. The environment room is initially created with only one structure of type "floor" that is named "ground". HVAC plenum rooms are not allowed to contain structures. All other rooms are created with three structures, one of each type. The area of the structures created in a room are automatically calculated to be the appropriate areas for a cube with the volume of the room. If you change the volume of a room KBERT will prompt you to allow KBERT to automatically re-adjust the areas of these three default structures. In the present version of KBERT only floor structures have an effect on analysis results, since gravitational settling is the only aerosol deposition model included. To accommodate future KBERT versions, where deposition mechanisms onto walls and roofs are envisioned, users are encouraged to define rooms with the appropriate wall and roof areas as well as floor areas. Structures are not shown visually on the KBERT screen; however, the deposition mass on structures is shown in the inspect bar when a room is selected. Structures may be added or removed by selecting the "Settled Matl" option button in the Edit Room dialog box and then clicking on either the "Add" or "Del" button under the structure list on the 
left hand side. An existing structure is edited by double clicking on the appropriate name in this list.

\subsubsection{Flowpaths}

Three types of flowpaths are used to connect rooms in a facility. The first type is a standard flowpath, which is used to represent doorways, windows, and other interconnections such as pipes. The second type is an HVAC source duct, which is used to represent flow into a room from the HVAC plenum room as a result of the HVAC system operation. The third type is an HVAC return duct, which is used to represent air and airborne material flow from a room back into the HVAC plenum room.

Standard flowpaths are shown on screen as black lines. The shape of the connecting line is automatically determined from the relative locations of the connected rooms. An arrow is placed on either side indicating the direction of gas flow through the flowpath. If flow is in both directions through the flowpath, an arrow will not be shown. Source HVAC ducts are shown as red arrows on the left side of rooms. Return HVAC ducts are shown as green arrows on the right side of rooms. Source HVAC ducts representing fresh air to the facility and return HVAC ducts representing exhaust from the facility are shown as green and red arrows on the HVAC plenum. The characteristics of flowpaths are described within the Flowpath dialog box that is accessed by double clicking anywhere on the flowpath of interest. The Flowpath dialog box can also be accessed by double clicking on the flowpath name of interest in the Run Accident Simulation dialog box.

HVAC source and return ducts must be identified with a given HVAC plenum. HVAC ducts can be specified in the environment room to represent fresh air flow into a facility and exhaust from a facility. If fresh air flow is to be kept separate from facility air recirculation, then two or more HVAC plenums should be included and the environment HVAC ducts should be entered on a separate HVAC plenum from the other HVAC ducts. New flowpaths are added by selecting either the "Doorway", "Source Duct", or "Return Duct" option under the Insert menu or by selecting any of the three corresponding shortcut buttons from the toolbar.

\subsubsection{Filters}

Filters may be specified to trap airborne materials on any flowpath, including doorways and HVAC ducts and are shown on screen as rectangular gray boxes. Although one would normally not include a filter on a doorway, this is allowed because standard flowpaths are also used to represent pipes which can be filtered. Each filter may be given a unique removal efficiency. Only airborne aerosol material are affected by filters; nonaerosol materials pass through filters unaffected. Filters are specified by first editing the flowpath where they are located and then pressing the "Filter" button in the Flowpath dialog box.

\subsection{Workers}

Workers are represented within a facility either individually or as groups that move together. Each worker or worker group is represented on screen as a small yellow square 
within one of the rooms. Workers may be moved from room to room at any time by dragging the appropriate yellow box with the mouse. Workers may not be added or dragged to HVAC plenum rooms; however, they can be added to the environment room. Because it is easy to accidentally drag and drop a worker to the environment room, users are prompted to confirm such an action when it occurs. Each worker or worker group can be given its own evacuation plan which defines how the worker(s) move following the initiation of an accident. Finally, each worker can be given personal protective equipment consisting of either skin protection, full or half mask, self contained breathing apparatus, and shine shielding using options in the Worker dialog box. The Worker dialog box is accessed by double clicking on the appropriate yellow square for the worker of interest. Workers may also be accessed by double clicking on the worker name in the Run Accident Simulation dialog box. New workers are added to a room by first clicking on the room and then selecting "Worker" under the Insert menu. Also, when a room is created the user is asked if a new worker should be automatically added to the room.

\subsection{Materials at risk and events}

Materials at risk and events are specified in the Event dialog box to represent an accident that has occurred in a facility. A new event is added to a room by selecting the "Events/MAR" option button in the Room dialog box and then pressing the "Add" key under the events list. This invokes an intuitive dialog box interface into the Mishima database. This database includes data for release fractions and respirable fractions for materials that have been subjected to a variety of stresses, such as fires, spills, and explosions. KBERT does not handle criticalities. An important feature of KBERT is that only realistic combinations of release data, stresses and materials at risk can be utilized in the simulation. Unrealistic combinations are inaccessible from the Event dialog box. Rooms that have events and materials at risk defined in them will be shown on screen with a red bar on the bottom.

The Mishima database accessed in KBERT provides either a one time airborne release fraction, (ARF), or a continuous airborne release rate, (ARR $(\mathrm{kg} / \mathrm{s})$ ). The mass (M) of material released into the atmosphere from an event in a given time step is:

$$
\begin{array}{rlr}
M & =M A R \cdot A R F & \left(t=t_{s}\right) \\
& =M A R \cdot A R R \cdot d t & \left(t>t_{s}\right)
\end{array}
$$

where $t_{s}$ is the event start time that is specified in the Run Accident Simulation dialog box. Normally this start time is equal to zero. Note that the ARF is only used on the first time step. The released material will not begin to distribute through the facility and affect workers until subsequent time steps.

When mass $M$ is released into the atmosphere of the room, the following equation is used to calculate the respirable fraction of the material: 


$$
R F(t)=\frac{R F(t) \cdot M(t)+R F \cdot M}{M(t)+M}
$$

where $M$ is the mass of material released during this time step, $R F$ is the respirable fraction of the material at risk as taken from the database, $M(t)$ is the mass of the same material present in the atmosphere before this time step, and $\mathrm{RF}(\mathrm{t})$ is the respirable fraction of the material in the atmosphere before this time step. Often, $R F$ and $R F(t)$ will be the same so the above equation simply becomes $R F(t)=R F$. However, in cases where $R F$ is calculated it can change in time since RF is recalculated at the beginning of every time step. The above equation ensures that the appropriate fraction of the airborne material is treated as respirable.

The values of $A R F, A R R$, and $R F$ are extracted from the database and shown in the Event dialog box. If any of these values are calculated, it will not be shown. Instead, the word "Formula" will appear. To display the calculated value, you can click on the "User Specified" option button. This will evaluate the formula so that the initial (time $=0$ ) calculated value is displayed.

There are actually three values for ARF, ARR, and RF that are in the database: minimum, nominal, and bounding values. Initially the nominal value is shown in the Event dialog box. A pull-down menu is provided to allow the user to select and show either the minimum, nominal or the bounding values. The Run Accident Simulation dialog box has a similar set of option buttons that are used to dictate which set is actually used in the analysis.

\subsection{Flows and equation of state}

Air and airborne contaminant flow are driven by user specified flow rates through the flowpaths. The user is required to specify the volumetric flow rate in $\mathrm{m}^{3} / \mathrm{s}$ for each flowpath in the facility. KBERT uses the specified flow rates to move air and airborne contaminants (aerosols and vapor phase radionuclides) between the interconnected rooms as described below. Secondary events caused by release incidents are not simulated. Only the events specified by the user affect air flow.

Air in KBERT is assumed to be composed of $79 \%$ nitrogen and $21 \%$ oxygen; however, this can be readily made more flexible in future versions if it is determined that such flexibility is useful. The time dependent conservation equation for gas species $\mathrm{k}$ in room $\mathrm{i}$ is given by:

$$
\frac{d m_{i, k}}{d t}=\sum_{j \rightarrow i}\left(\frac{m_{j, k} \cdot Q_{j i}}{V_{j}}\right)-m_{i, k} \cdot\left(\frac{\sum_{i \rightarrow j} Q_{i j}}{V_{i}}\right)
$$

where, $m_{i k}$ is the mass of gas species $k$ in room $i, V_{i j}$ is the volume of room $i, Q_{i j}$ is the volumetric flow rate from room $i$ to room $\mathrm{j}$. Excluding the effects of filters, an identical equation is used to calculate the flow of airborne contaminants with the gas flow. This 
approach hinges on the assumption that airborne contaminants are sufficiently small in size and mass that they do not affect the gas flow. A rule of thumb that quantifies this assumption is that average distance between particles is at least 10 times the particle diameter. A further assumption is that contaminants flow between rooms with the gas flow with very little slip, i.e. at the same velocity as the flow. Technically, this is valid for very low flow rates, and is a reasonable approximation for most cases. When filters are present, the flow of aerosols between rooms is modeled according to the following modified version of the conservation equation:

$$
\frac{d a_{i, k}}{d t}=\sum_{j \rightarrow i}\left(\frac{a_{j, k} \cdot Q_{j i}}{V_{j}} \cdot\left(1-\varepsilon_{j i}\right)\right)-a_{i, k} \cdot\left(\frac{\sum_{i \rightarrow j} Q_{i j}}{V_{i}}\right)
$$

where $a_{\mathrm{i}, \mathrm{k}}$ is the mass of aerosol material $\mathrm{k}$ in room $\mathrm{i}$, and $\varepsilon_{\mathrm{ji}}$ is the filter removal efficiency in flowpath ji. The fraction that does not flow through to room i gets trapped in the filter.

The enthalpy flow between rooms is given by a similar expression for the time rate of change of internal energy, $U$, in a room:

$$
\frac{d U_{i}}{d t}=\sum_{j \rightarrow i}\left(\frac{\left(U_{j}+P_{i} V_{j}\right) \cdot Q_{j i}}{V_{j}}\right)-\left(U_{i}+P_{i} V_{i}\right) \cdot\left(\frac{\sum_{i \rightarrow j} Q_{i j}}{V_{i}}\right)
$$

where $\mathrm{P}$ is the pressure. The above equations are evaluated for all flowpaths to determine the end of time step gas and material masses and room internal energies. Once the internal energy is known the temperature, $\mathrm{T}$, of each room can be obtained from the equation:

$$
U_{i}=\sum_{k} m_{i, k} \cdot\left[h_{k}\left(T_{i}\right)-\frac{R T_{i}}{M W_{k}}\right]
$$

where $R$ is the gas constant, $M W_{k}$ is the molecular weight of gas species $k$, and $h_{k}\left(T_{i}\right)$ represents the specific enthalpy at temperature $T$ for species $k$ in room $i$. This equation simply equates the total energy in a room to the energy of the gases in the room. The term in square brackets is the specific internal energy of species $k$. KBERT includes specific enthalpy functions for nitrogen and oxygen gases. Note that the specific enthalpy functions are referenced to zero at $273.15 \mathrm{~K}$; therefore, the internal energy of a room, $\mathrm{U}=$ $\mathrm{H}-\mathrm{PV}$, will be negative for temperatures in the $300 \mathrm{~K}$ range. The solution to the above equation is obtained by iteration.

Once the temperature and gas masses of each room are known, the new pressure is evaluated using the ideal gas law equation of state:

$$
P_{i}=\left(\sum_{k} \frac{m_{i, k}}{M W_{k}}\right) \frac{R T_{i}}{V_{i}}
$$

In a uniform temperature facility, if the user specified flows are balanced (i.e., if all incoming volumetric flows to a room match the outgoing flows), then the pressure 
calculated from the above equation will always equal the initial pressure. This will not be true if the flows are changing in time or if some rooms have a different initial temperature.

The above equations are solved using first order explicit time integration steps. The size of the integration steps is controlled by the relative magnitude of the highest user specified flow rate and the smallest room volume in the facility. The time integration step is set to allow only $10 \%$ of the volume of the smallest room to be exchanged in a single time step. If this constraint results in a time step larger than the user selected time step, then the flow and equation of state integration time step is simply taken to equal the user specified time step.

\subsection{Dose and consequence models}

Mechanistic models are included in KBERT for calculating dose and consequences to infacility workers. The four dose pathways considered in KBERT are inhalation, cloudshine, groundshine, and deposition on skin. Health effects models are included for latent cancers and acute injuries and deaths. These models are described in detail by Monroe [1994] $]^{3}$. Information about the specific implementation of these models in KBERT is provided in this section. The reader is referred to Monroe [1994] for detailed information about the dose models, including information about the dose conversion factors.

Inhalation dose received by a worker in a room during a time step is directly related to the activity in the room, the breathing rate of the worker in question, and a dose conversion factor that relates inhaled activity to dose. The activity in the room atmosphere or air is calculated as the sum of the activity of all airborne radioactive materials. Half lives of all materials that can be airborne in KBERT are automatically extracted from the KBERT materials database. A default worker breathing rate $\left(1.7 \mathrm{e}-4 \mathrm{~m}^{3} / \mathrm{s}\right)$ is provided, but the user may change this to any value desired. The dose conversion factors are stored in the KBERT database for each material. The appropriate conversion factor for each radioactive isotope is automatically extracted from the database and used in the inhalation dose calculation. If a worker has an evacuation plan, then the dose rate can change as the worker moves from one room to another. The dose rate in the new room will be based on the activity in that room. The cumulative inhalation dose received at any given time is equal to the sum of the doses received during all time steps leading up to that time.

Cloudshine dose calculations follow an identical logic. The cloudshine model of course uses different dose conversion factors from the KBERT database. Again, the appropriate conversion factor that relates airborne activity to cloudshine dose is automatically extracted from the KBERT database and used in the dose calculation. The cloudshine model in KBERT is a slightly modified form of that described in Monroe [1994] which includes a geometric factor to account for the finite nature of rooms. This factor will be described in a forthcoming updated version of the dose report.

The groundshine model is based on the amount of radioactive material deposited on structures in the facility. As aerosol deposits on structures, KBERT calculates the mass and activity attributed to deposited material. The groundshine model uses this activity. The appropriate dose conversion factor that relates surface specific activity to groundshine 
dose for each deposited radioactive material is automatically extracted from the KBERT database and used in the groundshine model.

The above three dose pathways are evaluated for the body organ categories list below, where a distinct dose conversion factor is obtained from the KBERT database for each radionuclide, dose pathway, and organ category (except skin):

$\begin{array}{ll}\text { Adrenals } & \text { Bladder } \\ \text { Bone } & \text { Breast } \\ \text { EDE } & \text { ICRP60ED } \\ \text { Kidneys } & \text { Liver } \\ \text { Lower Large Intestine } & \text { Lungs } \\ \text { Ovaries } & \text { Pancreas } \\ \text { Red Marrow } & \text { Small Intestine } \\ \text { Spleen } & \text { Stomach } \\ \text { Testes } & \text { Thymus } \\ \text { Thyroid } & \text { ThyroidH }\end{array}$

Note that the "EDE" category on this list is an effective organ for an equivalent whole body dose. This is the dose that is reported in the main output. The doses to specific body organs are used in the calculation of specific health effects. The "ICRP60ED" category is unused at this time. Categories are based on the ICRP $26^{6}$ standard.

The skin dose is evaluated for only one body organ, the skin. The model for skin dose is similar to groundshine. The only difference is that the dose is driven by the amount of radioactive material that has deposited onto the skin. This is calculated and stored exactly as if the entire skin area were a floor in the room. Obviously the entire skin area will not be horizontal facing up therefore, this assumption will result in a conservative estimate for skin dose. Unlike the other dose models, the dose conversion factor relating activity to dose is the same for all radionuclides in the skin dose model.

\subsection{Aerosol removal by gravitational settling}

Materials at risk released from events enter the atmosphere of rooms as aerosols. The size of the released aerosol material is calculated as a function of the respirable fraction, $R F$, obtained from the release database as follows ${ }^{4}$ :

$$
\begin{aligned}
D_{\text {mean }} & =10^{-5} \mathrm{~m} & & \text { if } R F=0.0 \\
& =10^{-6} \mathrm{~m} & & \text { if } R F=1.0 \\
& =10^{-(5+R)} \mathrm{m} & & \text { otherwise. }
\end{aligned}
$$

This size is important because it is used to calculated the aerosol settling rate by gravity. The following equation is used to evaluate the settling velocity of aerosol in a room:

$$
V_{g}=\frac{D_{\text {mean }}^{2} \cdot 1000 \cdot g \cdot C_{s}}{18 \mu} \quad, \quad C_{s}=1+\frac{2 \lambda}{D_{\text {mean }}}\left(F_{\text {slip }}+0.4 \cdot e^{-\left[\frac{1.1 \cdot D_{\text {mean }}}{2 \lambda}\right]}\right) .
$$


where $\mu$ is the viscosity of air $\left(1.8 \times 10^{-5}\right), g$ is the acceleration of gravity (9.8), $\lambda$ is the mean free path of air $\left(6.9 \times 10^{-8}\right)$, and $\mathrm{F}_{\text {slip }}$ is a slip factor (1.257). As this equation shows, the gravitational settling velocity, $\mathrm{V}_{\mathrm{g}}$, is a strong function of the airborne particle size. This equation was taken from the CONTAIN code from Washington [1990] $]^{5}$ which is routinely used to perform nuclear reactor safety analyses.

The settling velocity is used to calculate the deposition rate of airborne aerosol on floors and on the skin of workers in rooms. The rate of aerosol removal onto a given floor structure is given by:

$$
\frac{d m}{d t}=V_{g} \cdot \frac{A \cdot d t}{V o l}
$$

where $V_{g}$ is the settling velocity given above, $A$ is the surface area of the structure or of skin, $\mathrm{m}$ is the mass of aerosol in the room atmosphere, and Vol is the volume of the room. Additional deposition mechanisms and other aerosol topics are discussed in Heames $[1994]^{2}$ and could be readily implemented.

\section{Input Instructions}

This section describes the various dialog boxes in KBERT in detail. Each of the dialog boxes can be opened from the Insert main menu for the KBERT application or by double clicking the facility element of interest. In each section a picture of the dialog box is shown and each control on that box is discussed. Note also that the sub-section numbers parallel those in Section 3

\subsection{Facility elements}

\subsubsection{Rooms}

Rooms are defined or modified using the Room dialog box shown below. Airborne material may be added from the default view of the Room dialog box. 


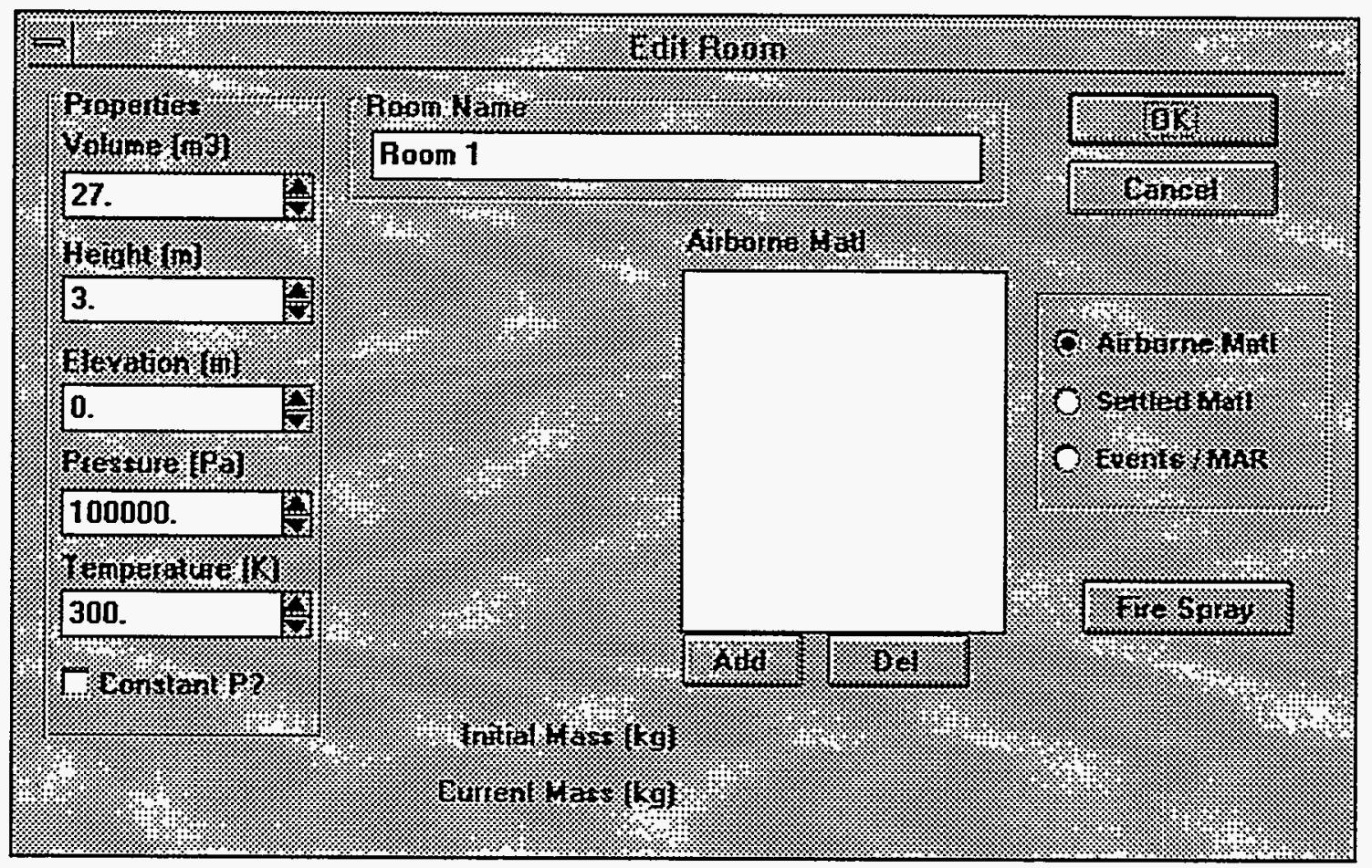

The Room dialog box changes views when a different option button is selected on the right hand side of the box. The view with the "Settled Matl" option selected is shown below. Settled material may be added to any of the room structures from this screen.

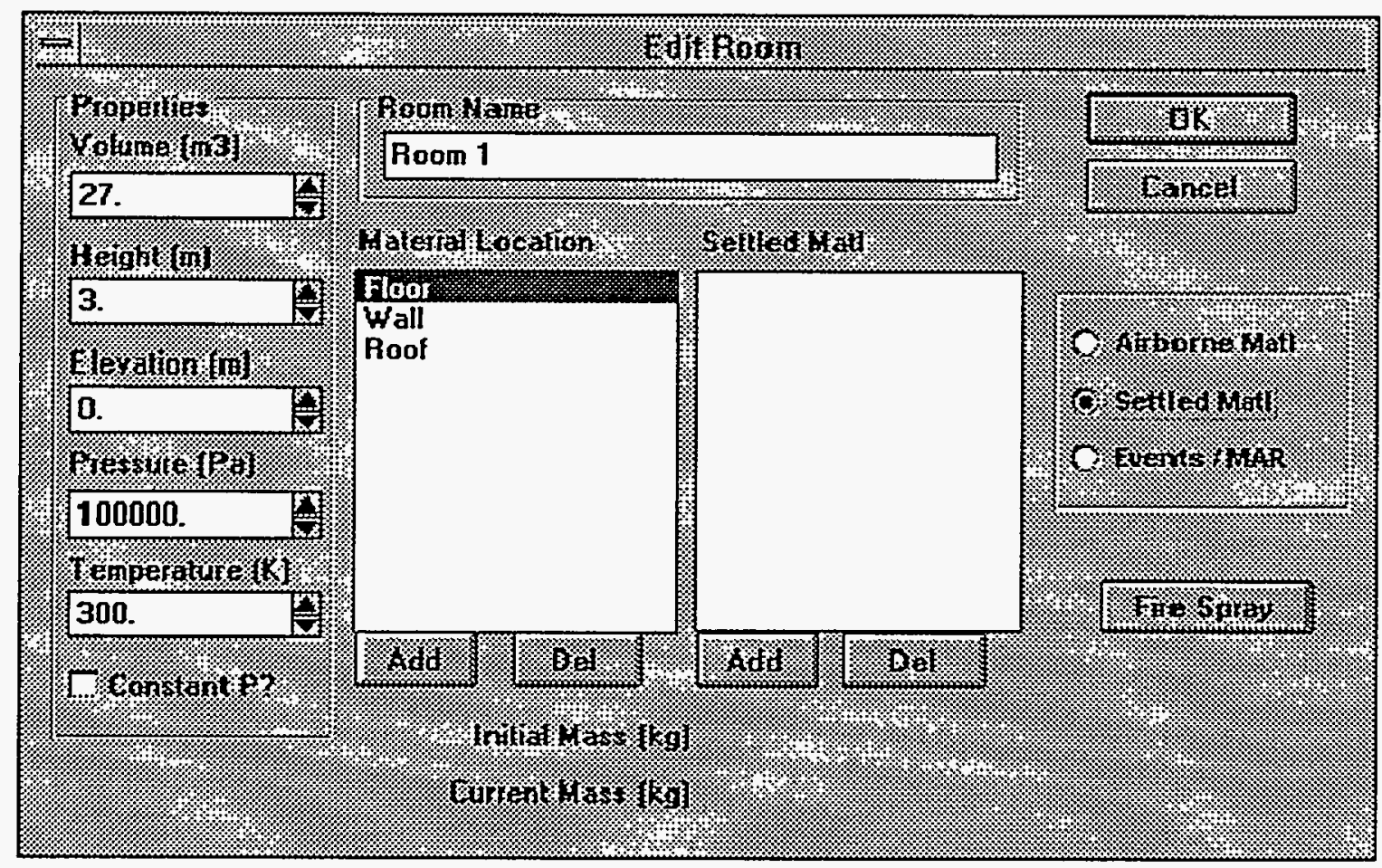


The Room dialog box view with the "Events/MAR" option selected is given below.

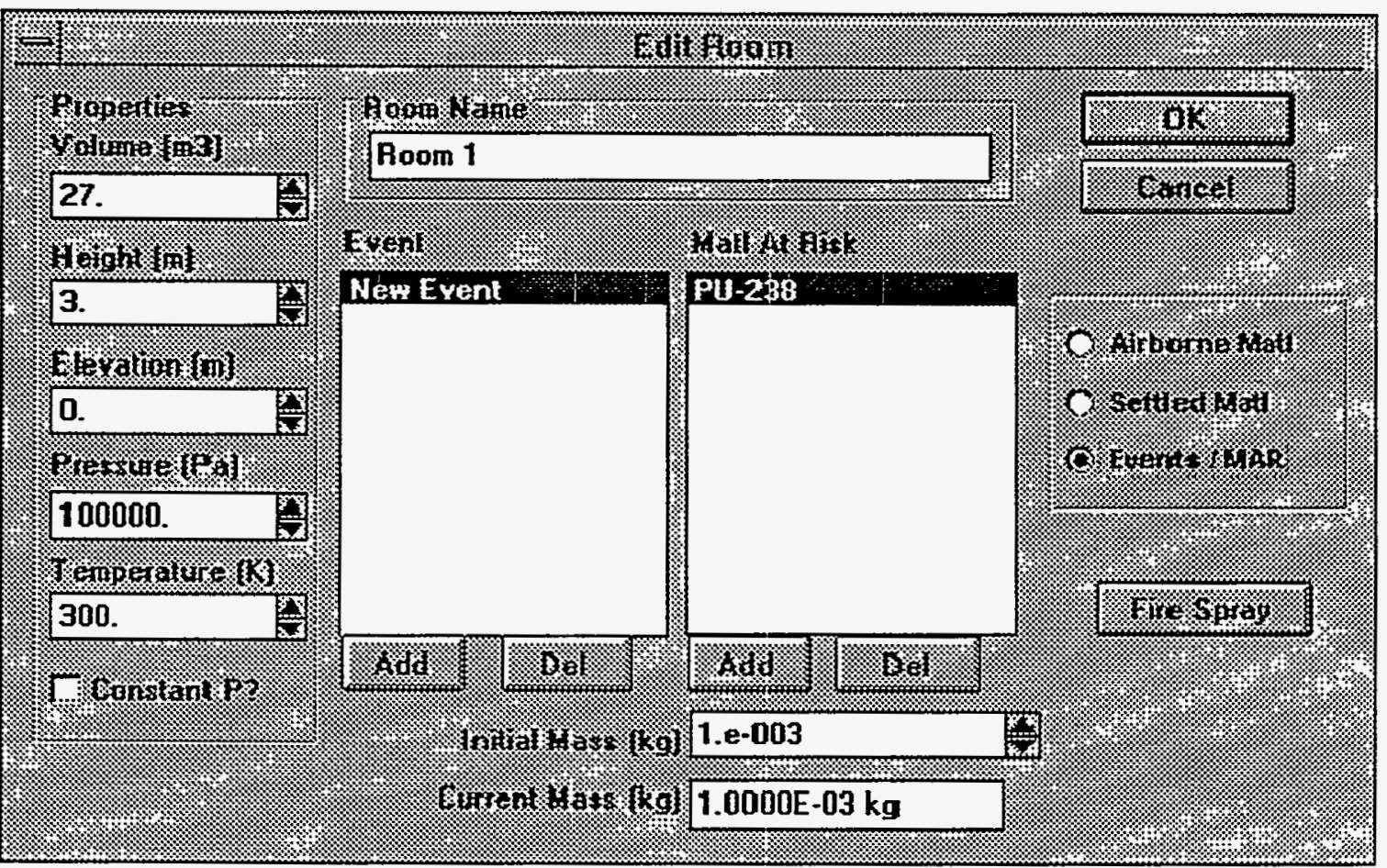

Each control in the Room dialog box is explained below.

Room Name

Volume

Height

Elevation
Edit box used to specify a unique name for the room. This name is referred to in the results presented in the Run Accident Simulation dialog box and in the Inspect bar. By default a unique generic name (Room \#) is created when a new room is added, but users are encouraged to give rooms specific names that have meaning to them.

Edit box used to specify the volume of the room. The volume must be positive. The size of the room on screen will be proportional to the value specified here. This value is also used to calculate the default areas of structures created in this room.

Edit box used to specify the height of the room. The height of the room on screen will be proportional to this value. This value is also used to calculate the aerosol gravitational deposition rate and the default areas of structures in the room.

Edit box used to specify the vertical elevation of the room, where 0 is the ground floor. This value is presently unused, but users are encouraged to specify realistic values here because future flow models will make use of this information to calculate gravitational head. 
Pressure

Temperature

Constant P?

Option buttons

Airborne Matl

Settled Matl

Material Location

Edit box used to specify the initial pressure of the room. This value is presently not used, but it is calculated to change in time as gases flow through the facility. Future flow models in KBERT will make heavy use of this input.

Edit box used to specify the initial temperature of the room. Like the pressure, room temperatures are calculated as materials flow according to user specified flow rates. Future flow models will make heavy use of this input.

Check box used to tell KBERT to bypass the equation of state calculation for pressure in this room. If this is done, the pressure will always equal the initial pressure. To avoid inconsistencies, the equation of state will be used to calculate a temperature consistent with the initial pressure and the internal energy in the room.

A group of three option buttons, labeled Airborne Matl, Settled Matl, and Event/MAR used to select what is shown in the two list boxes in the middle of the dialog box. Only one of these buttons can be selected at a given time. When a different button is selected, the dialog box changes to show different information. The effect of selecting different option buttons is discussed further in the description of the list boxes below.

List box showing all materials initially present in the room atmosphere. This list box is only shown when the Airborne Matl option button is selected. Selecting any material in the list will result in the mass present being displayed in the Initial Mass and Current Mass edit boxes at the bottom of the dialog box. Double clicking on any material in the list will invoke the Materials dialog box described in Section 4.3.3.

List box showing materials present on a structure in the room. The materials shown are those on the structure highlighted in the Material Location list box (see the Edit Room dialog box view with the Settled Matl option selected above). The Settled Matl list box takes the place of the Airborne Matl list box when the Settled Matl option button is selected. Selecting any material in the list will result in the mass present showing in the Initial Mass and Current Mass edit boxes at the bottom of the dialog box. Double clicking on a material in the list will invoke the Materials dialog box described in Section 4.3.3.

List box showing the names of all structures in the room. Selecting any structure in the list will cause the materials on that structure to be listed in the Settled Matl list box (see the Room dialog box view with the Settled Matl option selected above). Double clicking on a structure in the list will invoke the Structures dialog box described in Section 4.1.3. 
Matl At Risk List box showing all materials at risk present in an event in the room. The materials shown are those associated with the highlighted event in the Event list box (see the Room dialog box view with the "Events/MAR" option selected above). The Matl At Risk list box takes the place of the Airborne Matl or Settled Matl list boxes when the "Events/MAR" option button is selected. Typically there will be one material associated with a given event; however, KBERT is not restricted to this. If multiple materials are present the mass shown in the Initial Mass and Current Mass edit boxes are the masses of the highlighted material at risk.

Add

Push buttons used to add objects to a room. The "Add" button on the left is used to add structures to the room if the "Settled Matl" option button is selected. An event may be added if the "Events/MAR" option button is selected. If the "Airborne Matl" option button is selected, the "Add" button on the left is not shown. The Add button on the right is used to add materials to either the atmosphere (if the "Airborne Matl" option button is selected) or a structure (if the "Settled Matl" option button is selected). If the "Events/MAR" option button is selected, the Event dialog box will be invoked (see Section 4.3). This is done because KBERT only allows certain materials to be added to certain events.

Del

Push buttons to delete objects from a room. The button on the left is used to delete structures from the room if the "Settled Matl" option button is selected. The highlighted event will be deleted if the "Events/MAR" option button is selected. If the "Airborne Matl" option button is selected, the "Del" button on the left is not shown. The "Del" button on the right is used to delete materials from the atmosphere (if the "Airborne Matl" option button is selected), from a structure (if the "Settled Matl" option button is selected), or from an event (if the "Events/MAR" option button is selected). After the "Del" button is pushed a confirmation dialog box will be shown; if No is selected the item will not be deleted; if Yes is selected the item is deleted.

\subsubsection{HVAC Plenums}

HVAC plenums are special types of rooms (see Section 3.1.2). The input options available in the Room dialog box apply also to HVAC plenums with one exception. The option buttons normally provided in the Room dialog box are not shown for HVAC plenums. This is because structures and events may not be added to HVAC plenums.

\subsubsection{Structures}

The Structures dialog box shown below is used to specify the name, area, and temperature of a structure within a room. The Structures dialog box is opened from the Edit Room dialog box when the "Settled Matl" option is selected. Double clicking the structure of interest in the material location list will open the dialog box. 


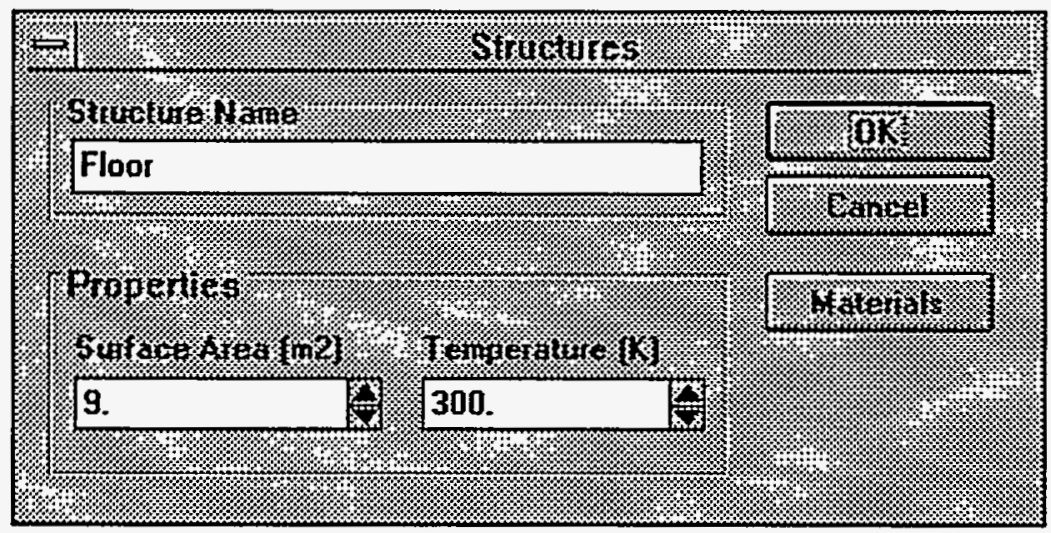

Each option in the Structures dialog box is explained below.

Structure Name Edit box used to specify a unique name for the structure.

Surface Area Edit box used to specify the surface area of this structure exposed to the atmosphere of the room where this structure is located.

Temperature Edit box used to specify the temperature of the structure. KBERT does not calculate changes in structure temperature, so this value is used throughout the entire analysis.

Materials Push button used to invoke the Edit Materials dialog box. This dialog box is used to specify materials on the structure. If radioactive materials are added to structures, they will contribute to the shine dose calculation. Materials are added by the software to floor structures throughout the analysis as a result of aerosol deposition by gravitational settling. This button is only used to manually add additional materials.

\subsubsection{Flowpaths}

\subsubsection{Standard flowpaths}

Standard flowpaths represent doorways, windows and other interconnections such as pipes, and are defined or modified using the dialog box shown below.

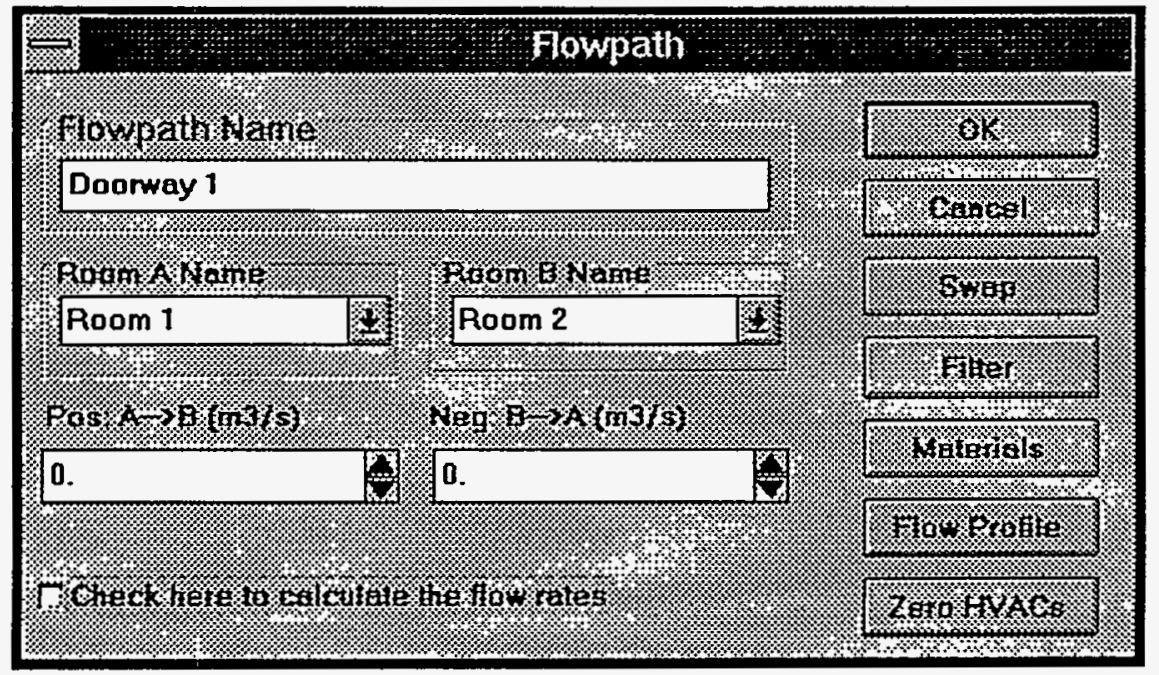


If the check box to calculate flow rates on the bottom of this box is selected, the flowpath edit box changes as follows:

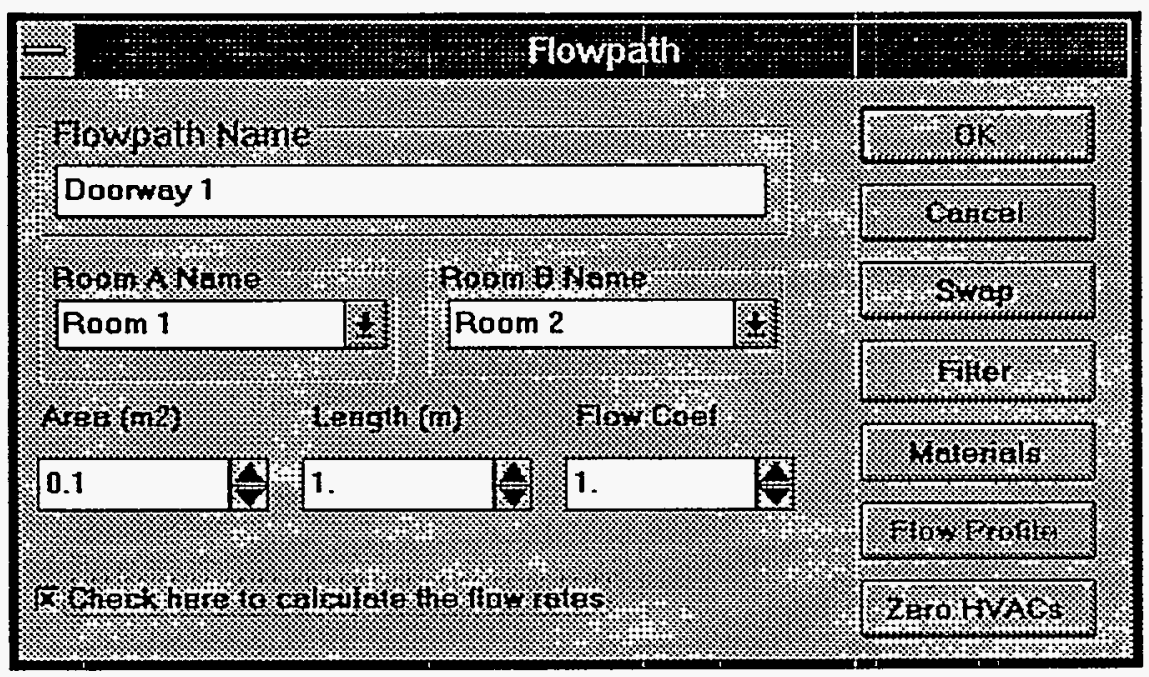

Each option is discussed below.

Flowpath Name Edit box used to specify a unique name for the flowpath.

Room A Name Drop down list to select one of the rooms to which the flowpath connects.

Room B Name Drop down list to select one of the rooms to which the flowpath connects.

Pos A->B Edit box to specify flow rate in $\mathrm{m}^{3} / \mathrm{s}$ from Room A to Room B. Note that a negative flow rate should never be specified. To represent flow from Room B to Room A, a positive value should be specified in the Neg B->A edit box described below. Flow can be specified in both directions by specifying a value in both edit boxes. This edit box is only available when the check box to calculate flow rates is not selected.

Neg B->A Edit box to specify flow rate in $\mathrm{m}^{3} / \mathrm{s}$ from Room B to Room A. Note that a negative flow rate should never be specified. To represent flow from Room A to Room B, a positive value should be specified in the Pos A->B edit box described above. Flow can be specified in both directions by specifying a value in both edit boxes. This edit box is only available when the check box to calculate flow rates is not selected.

Area Edit box to specify area of the flow path in meters ${ }^{2}$. This edit box is only available when the check box to calculate flow rates is selected.

Length Edit box to specify length of the flow path in meters. This edit box is only available when the check box to calculate flow rates is selected.

Flow Coef Edit box to specify the loss coefficient of the flow path. Values on the order of 1.0 are typical for this value. This edit box is only available when the check box to calculate flow rates is selected. 
Swap

Filter

Materials

Flow Profile

Zero HVACs
Push button to swap the names of Room A and Room B. This is needed to reverse the flows because the input checks do not allow one to set Room A name equal to Room B.

Push button to invoke the Filter dialog box. This dialog box is used to define the removal efficiency of the filter in the flowpath. Note that all flowpaths have a filter; however, initially the filter removal efficiency is set to zero. Only filters with non-zero removal efficiencies are shown on the main screen.

Push button to invoke the Materials dialog box for filters. This is simply a shortcut to first pushing the filter button and then pressing the materials button in the Filter dialog box.

Push button to invoke the Flow Profile dialog box. This dialog box is used to specify flow rates in both directions as a function of time and is shown and discussed in the Section 4.1.4.3. This option is only available when the check box to calculate flow rates is not selected.

Push button to set the flow rates in all HVAC flowpaths to zero. When this button is pushed the following Value Input dialog box is presented to the user to select the time beyond which the flows will be zero.

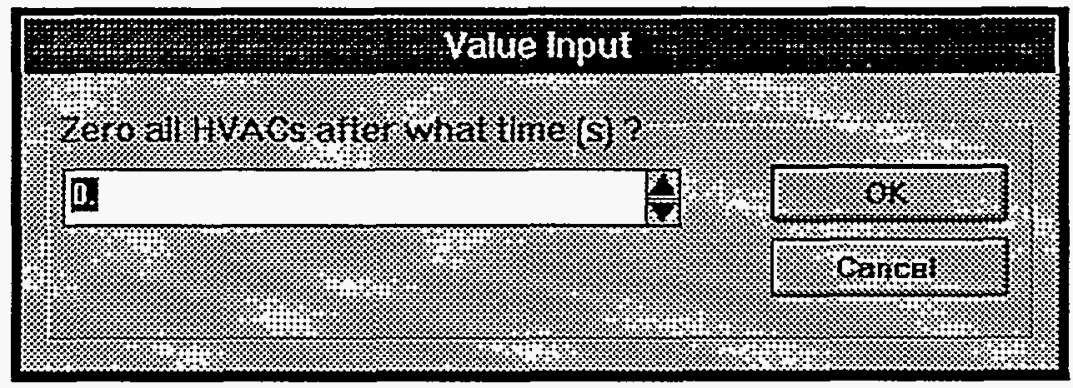

This feature is useful for simulating the shutdown of the HVAC system in a facility. To turn on the HVAC system after it has been turned off, use the time dependent flow profiles described in section 4.1.4.3.

\subsubsection{HVAC ducts}

HVAC ducts are specified using the dialog box shown below, which is similar to the dialog box for standard flowpaths. 


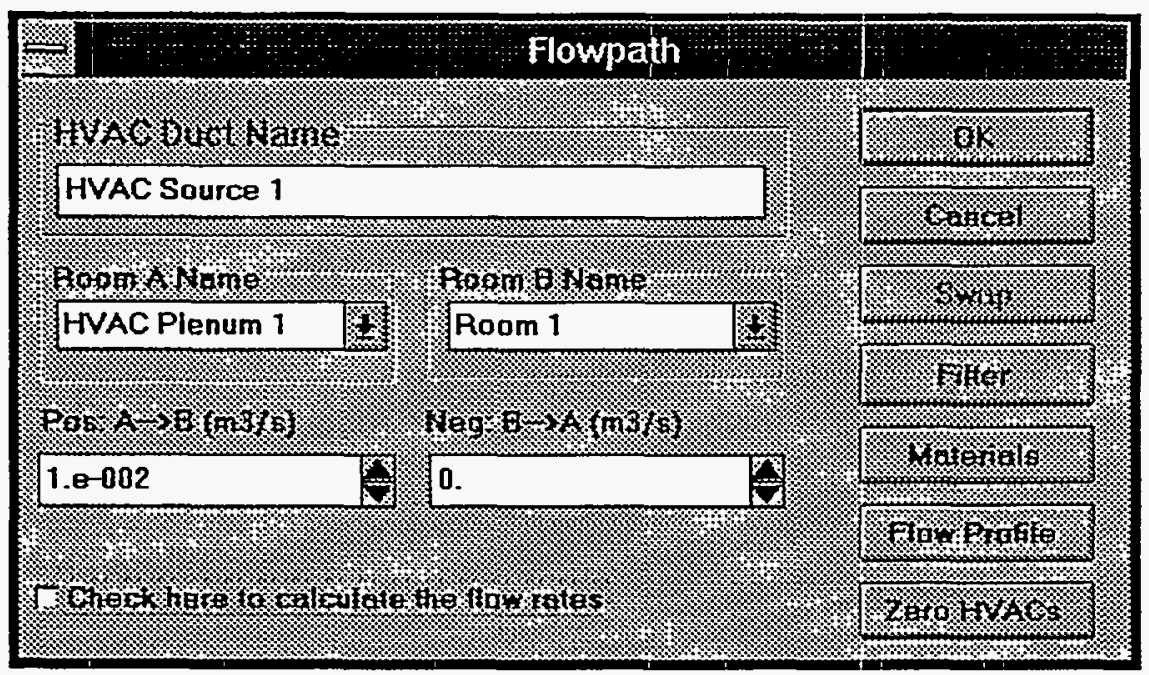

The one difference between this dialog box and the standard flowpath box is that the Room A drop down list only contains a list of the HVAC plenums in the facility. This is done because HVAC ducts connect rooms to HVAC plenums. Therefore, all HVAC ducts must have an HVAC plenum as the "Room A" room. Notice also that the "Swap" button is grayed and not available in the HVAC Duct dialog box because again, the "Room A" room must be an HVAC plenum.

\subsubsection{Time dependent flow profiles}

Flow rates as a function of time for standard flowpaths and HVAC ducts can be specified by pressing the "Flow Profile" button in the Flowpath dialog box. When this is done the following dialog box is shown. 


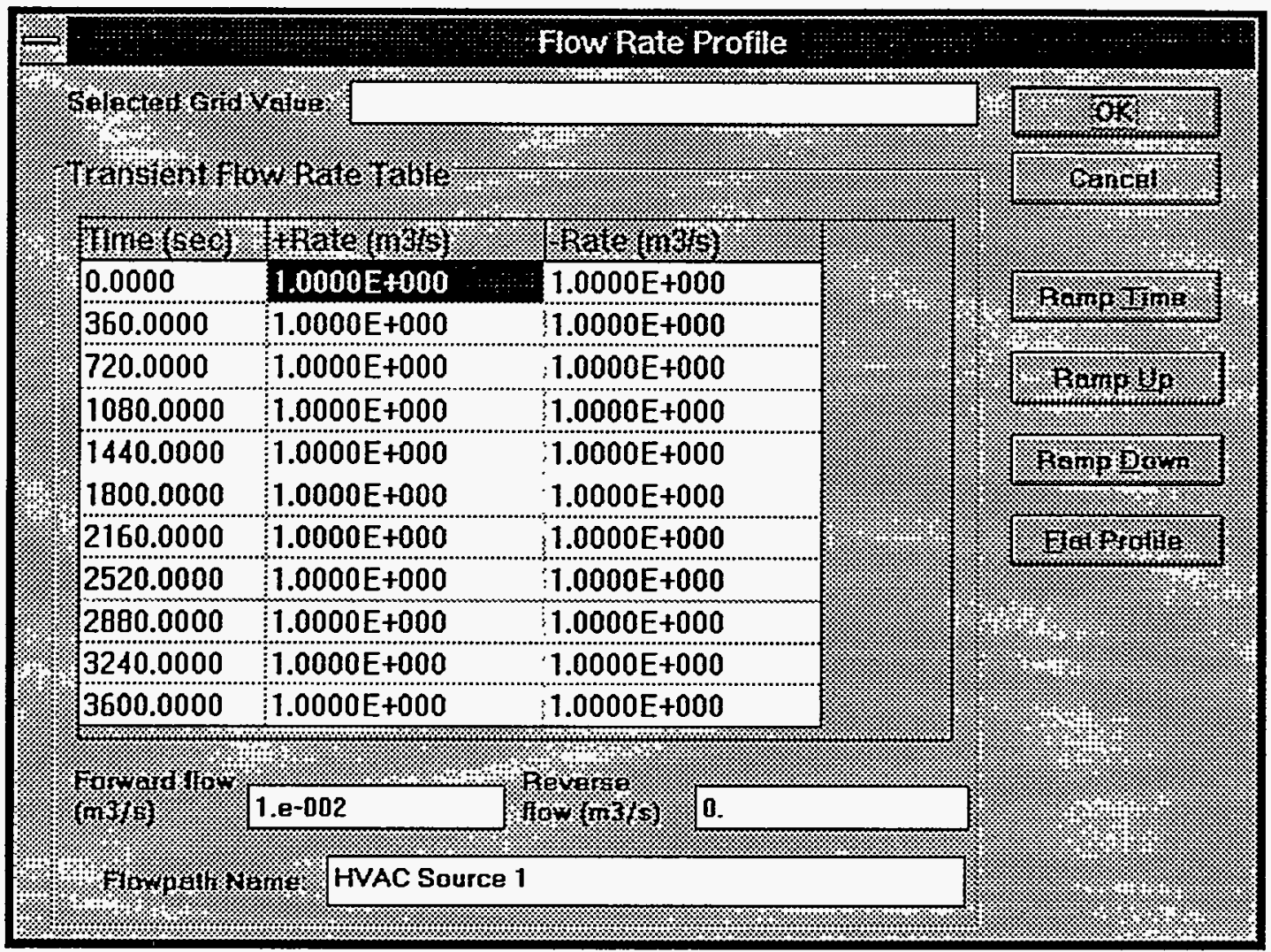

The controls in this dialog box are described below.

Selected Grid

Value

Time

+ Rate

-Rate

Forward flow
Edit box used to change values in the transient flow rate table.

The first column in the table which holds the time values which determine when during the simulation the forward and reverse flow rates will take effect.

The second column in the table holds the flow rates in the positive direction which will occur during the simulation. The rates specified here are multiplied by the Forward Flow multiplier described below. Typically one would specify 1.0 for the Forward Flow multiplier to negate its effect when using the table to supply specify time-dependent flow values.

The third column in the table holds the flow rates in the negative direction which will occur during the simulation. The rates specified here are multiplied by the Reverse Flow multiplier described below. Typically one would specify 1.0 for the Reverse Flow multiplier to negate its effect when using the table to specify time-dependent flow values.

An edit box used to set the steady-state value of the flow rate in the positive direction in the event that the transient flow rate table is not used. As noted above, the value here is multiplied by the values in the +Rate table. By default the flow rate table has no affect because it has all $1.0 \mathrm{~s}$ in it. 
Reverse flow

Flowpath Name

RampTime

Ramp Up

Ramp Down

An edit box used to set the steady-state value of the flow rate in the negative direction in the event that the transient flow rate table is not used. As noted above, the value here is multiplied by the values in the - Rate table. By default the flow rate table has no affect because it has all $1.0 \mathrm{~s}$ in it.

An edit box used to set the name of the flowpath so that it can be identified elsewhere in the program, such as in the Run Accident Simulation dialog box in the list of ducts.

The Ramp Time button brings up a dialog box which allows you to reset the time column to evenly spaced values between zero and the ending time as specified below:

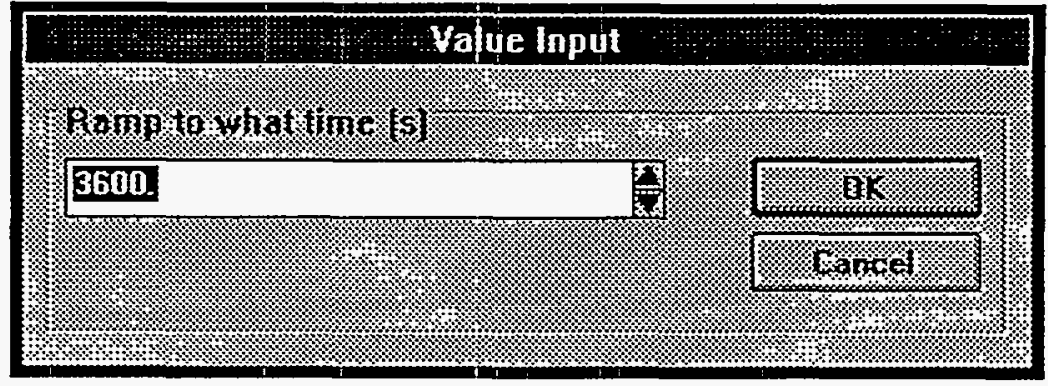

The Ramp Up button brings up a dialog box which allows you to set the selected flow column (+Rate or -Rate) to evenly spaced values between zero and the ending value as specified below:

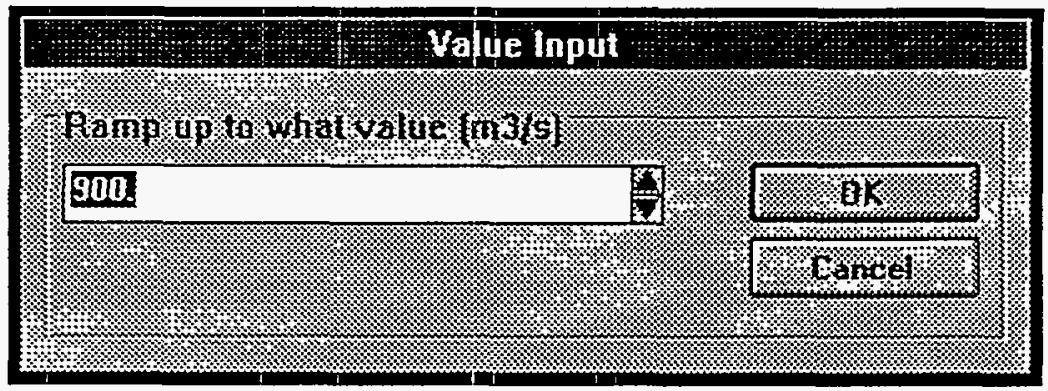

The + Rate column will be used if the mouse if first clicked on that column before the Ramp Up button is pressed. The -Rate column will be used if the mouse if clicked on that column before pressing the Ramp Up button.

The Ramp Down button brings up a dialog box which allows you to set the selected flow column (+Rate or -Rate) to evenly spaced values between the value specified below down to zero:

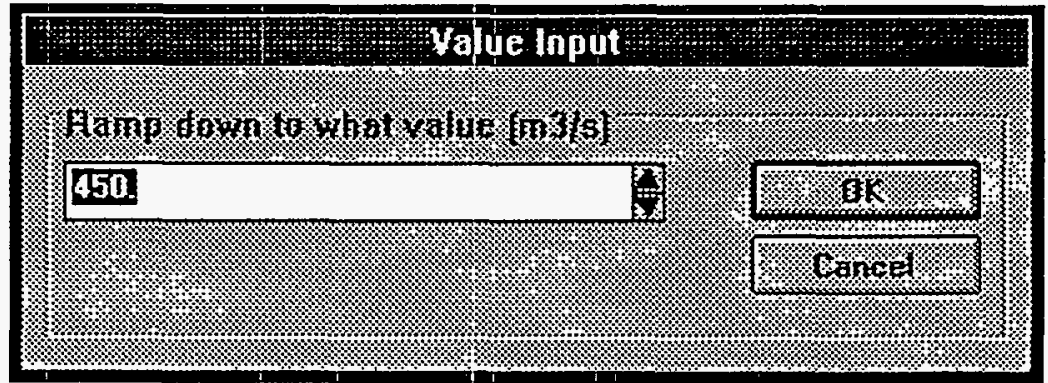


Flat Profile

The Flat Profile button brings up a dialog box which allows you to set all the selected flow column's values (+Rate or - Rate) to the value specified below:

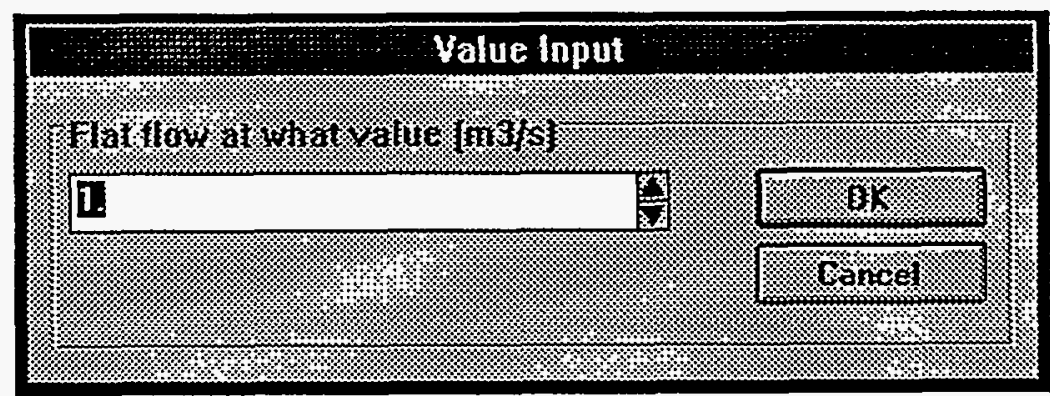

\subsubsection{Filters}

Filters may be added to any flowpath and simulate the removal of contaminant from the air.

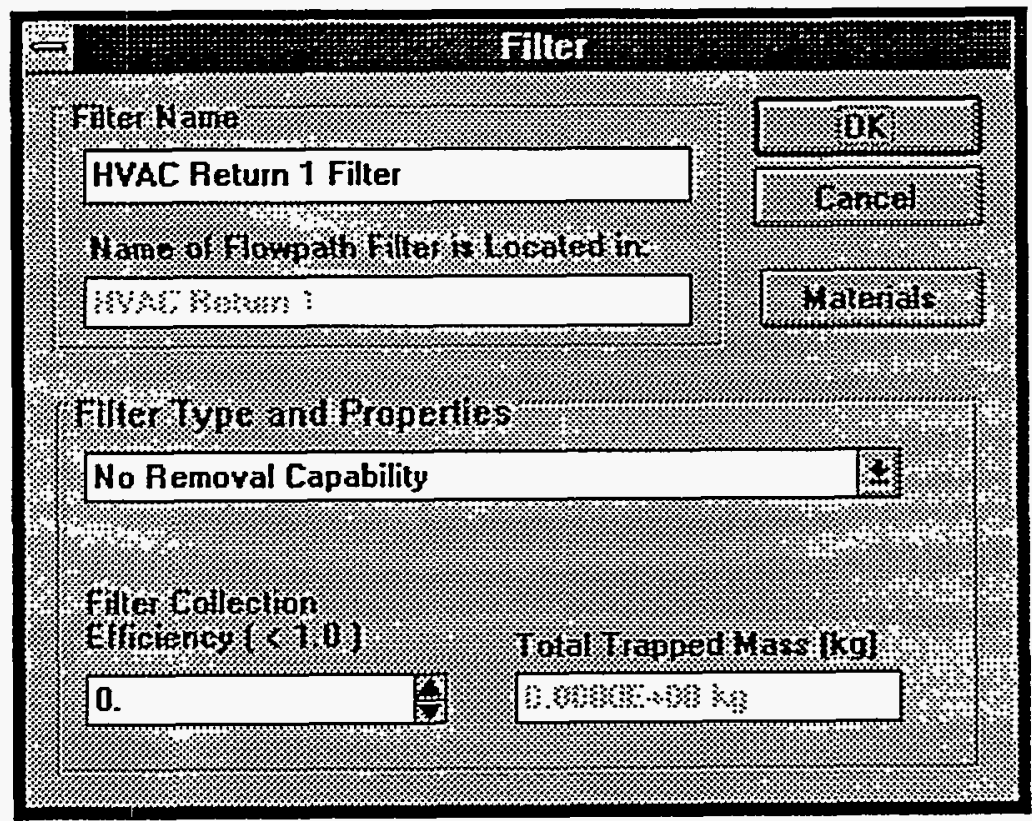

The controls in this dialog box are described below.

Filter Name

Location of Filter
An edit box used to set the name of the filter so that it can be identified elsewhere in the program.

A display only box used to show the name of the flowpath where the filter resides so that it can be identified elsewhere in the program, such as in the Run Accident Simulation dialog box in the list of ducts. 
A pull-down menu which lists the available pre-programmed choices for filter type, as shown below. The menu can be accessed by clicking on the right side of the box on the downward pointing arrow. This action will display the list as shown below. You may then select an option with a single mouse click. Each option has an associated collection efficiency value which is displayed in the edit box at the bottom left comer of the screen. The "User Specified" option does not suggest a value but lets you set the collection efficiency to any value between 0 and $100 \%$.

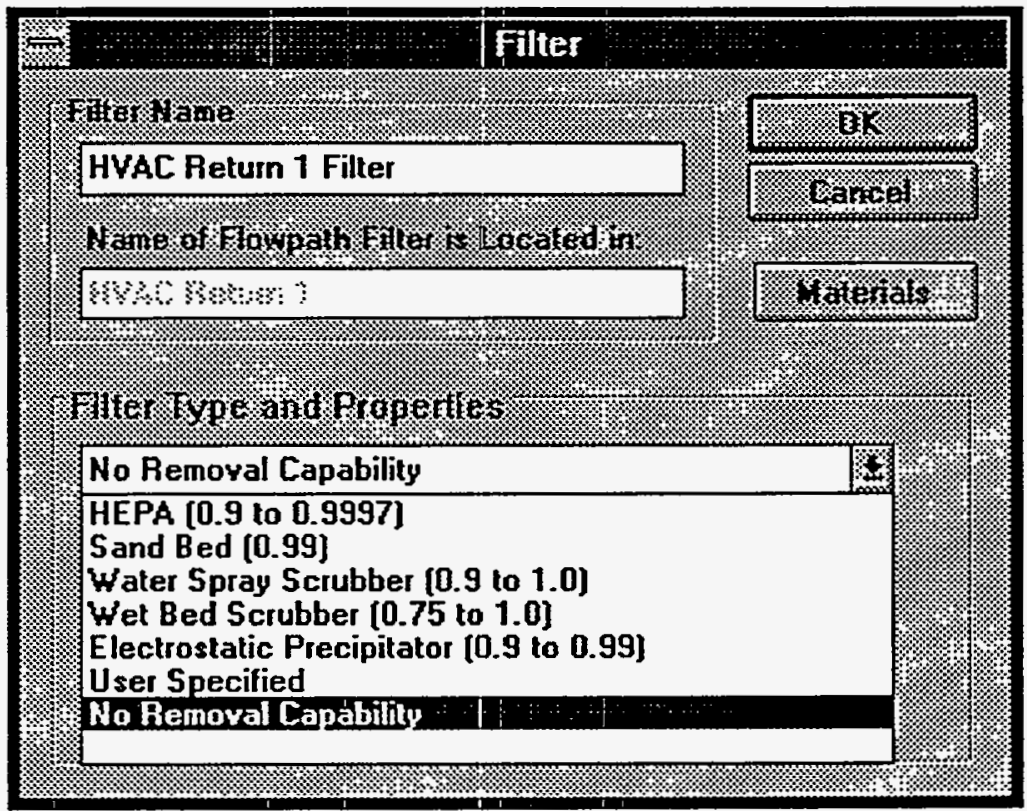

Collection Efficiency

An edit box which allows you to set or modify the filter collection efficiency to any value between 0 and $100 \%$. The value may be changed by typing in the box or by using the up and down arrows on the right side of the box.

Total

Trapped Mass

This box is display only and shows the total amount of material trapped by the filter at the current time in the simulation.

Materials

This button invokes the Materials dialog box which allows the user to assign an initial amount of filtered material to a flowpath filter. This dialog box is described in section 4.3.3.

\subsection{Workers}

\subsubsection{Physical characteristics}

Any definition of or modification to the physical characteristics of a worker must be done from the Worker dialog box. 


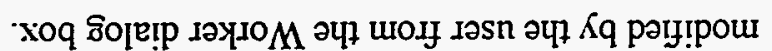

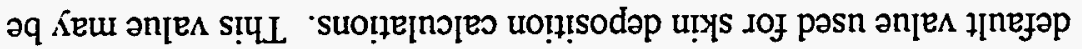

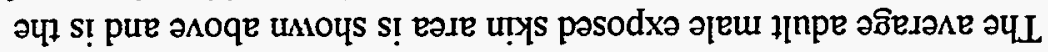

EวIe U!YS

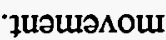

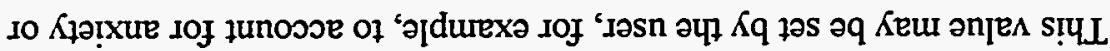

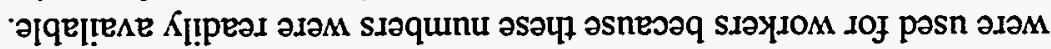

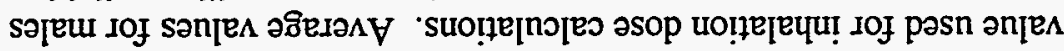

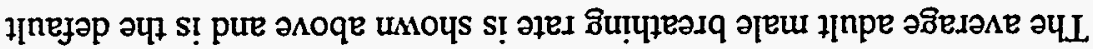

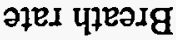

-sotukuaวs

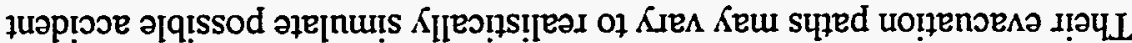

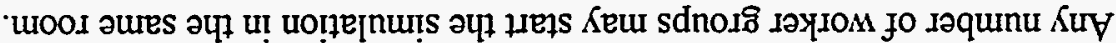

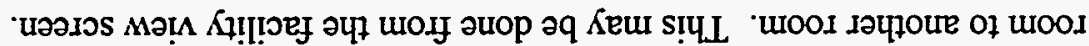

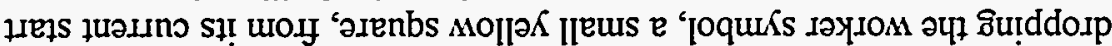

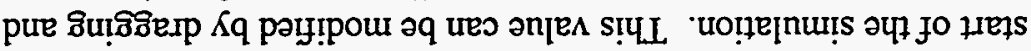

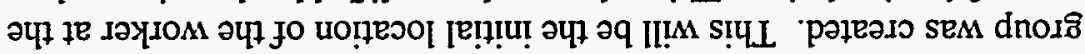

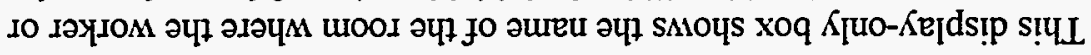

aureN wooy

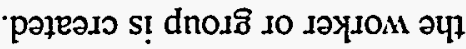

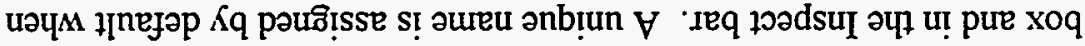

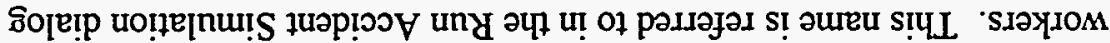

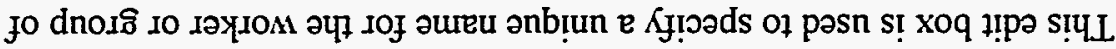

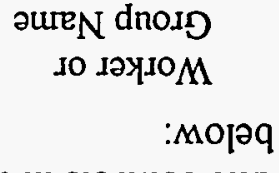

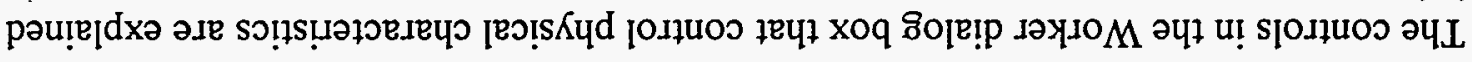

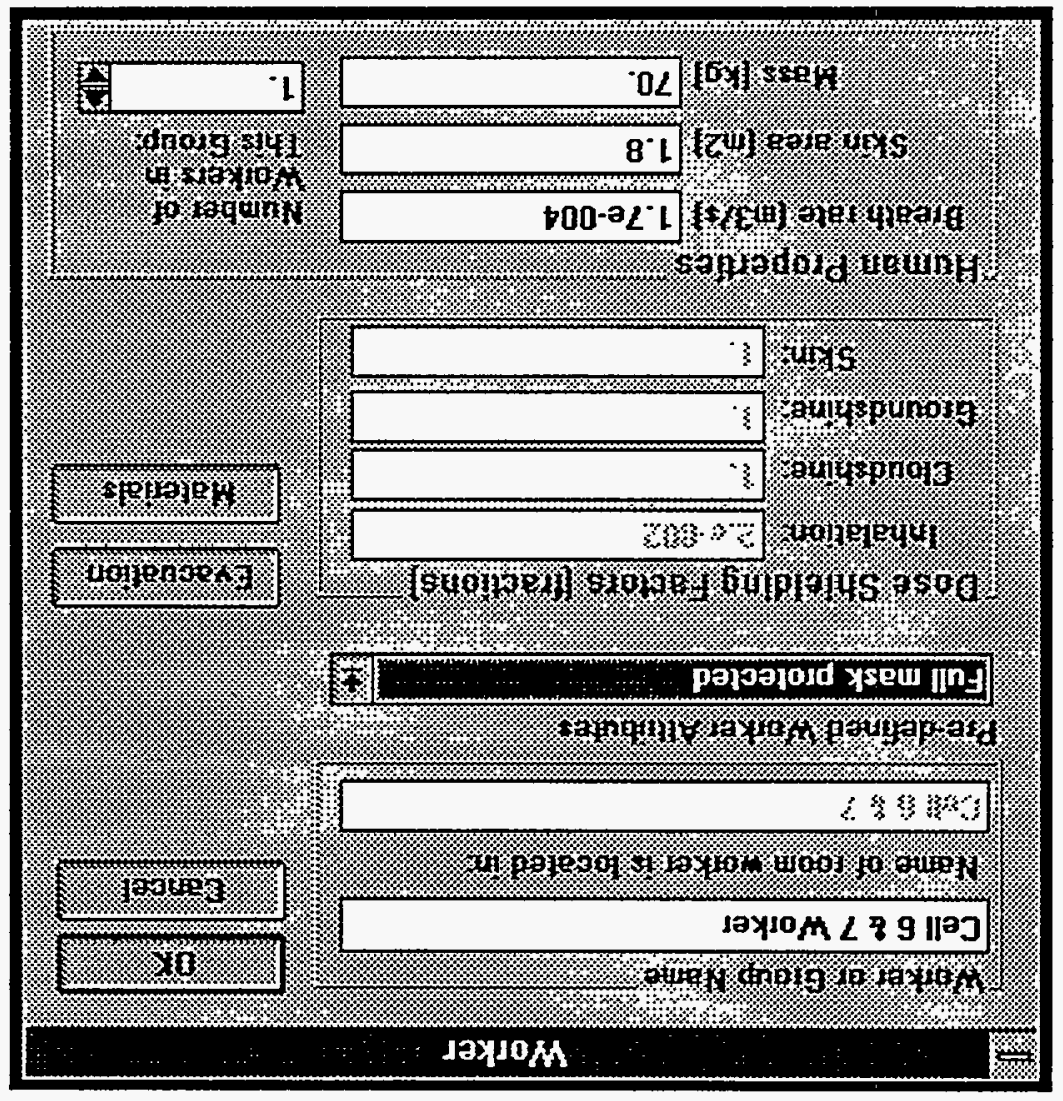


Mass The average adult male weight is shown above and is the default value used for dose calculations. This value may be modified by the user from the Worker dialog box.

Number of Workers

in This Group A worker symbol can indicate any number of workers who all evacuate together along the same route and at the same time. Set the number of workers to the number that you would like to be present in this group.

\subsubsection{Dose shielding factors}

A single pull-down menu in the Worker dialog box controls the dose shielding factors:

Pre-defined worker attributes

This pull-down menu is activated by clicking on the down-arrow on the right side of the box. This will bring up a list of choices of worker protection devices. When a selection is made, the protection factors associated with the choice will appear in the four categories of dose shielding factors. If "User defined" is selected, the four dose shielding factors will become accessible for editing and the user may then input values between 0 and 1 .

Dose Shielding Factors

There are four factors that influence radiation dose for KBERT. They include: Inhalation, Cloudshine, Groundshine and Skin Dose. A value of 1 in a category implies full exposure to the hazardous material; 0 in a category implies full protection.

\subsubsection{Evacuation plans}

Each worker or worker group can be assigned a particular evacuation path, which consists of a list of rooms visited and the time spent in each room during the evacuation. The evacuation plan is specified by pressing the "Evacuation" button in the Worker dialog box, which brings up the following Evacuation dialog box. 


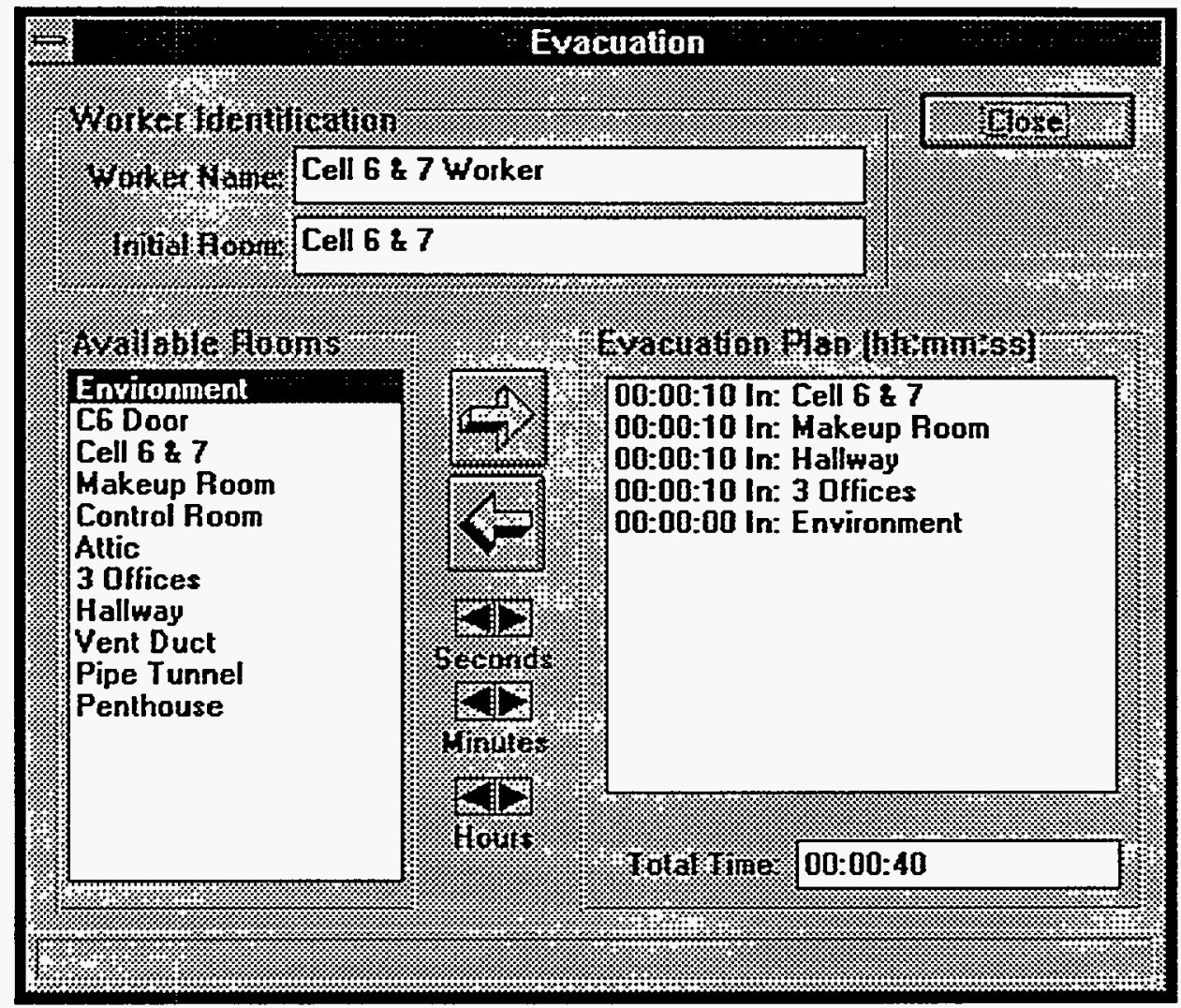

Each control in the Evacuation dialog box is explained below:

Worker Name This display only box is used to specify a unique name for the worker or worker group.

Initial Room This display only box is used to specify a unique name for the initial room where the worker will begin the simulation.

Available Rooms This box contains the names of all the rooms in the facility. The user can choose from this list when specifying the sequence of rooms along the evacuation route of the worker(s).

This control will add the selected room from the Available Rooms list to the evacuation plan. The room will be added immediately after the room that is currently selected in the evacuation plan.

This control will remove the selected room from the evacuation plan.

Evacuation Plan The evacuation plan lists the rooms that the worker(s) will visit while evacuating. The rooms are listed in the order in which the worker(s) will visit them. The time on the left side of each room in the plan indicate the amount of time the worker(s) will spend in that room. The worker must always begin the simulation in the room where the worker was created. The worker will remain in the last room on the evacuation plan for the duration of the simulation. 
Seconds, Minutes, Hours

These controls are used to add or subtract the indicated time unit from the duration time of the currently selected room in the evacuation plan.

\subsection{Materials at risk and events}

\subsubsection{Mishima database}

Access to the recommended release values from the Mishima [1993] ${ }^{1}$ database is through the Event dialog box shown below. The Event dialog box is opened from the Edit Room dialog box when the Events/MAR option is selected. Pressing the "Add" button or double clicking an existing event will open the dialog box.

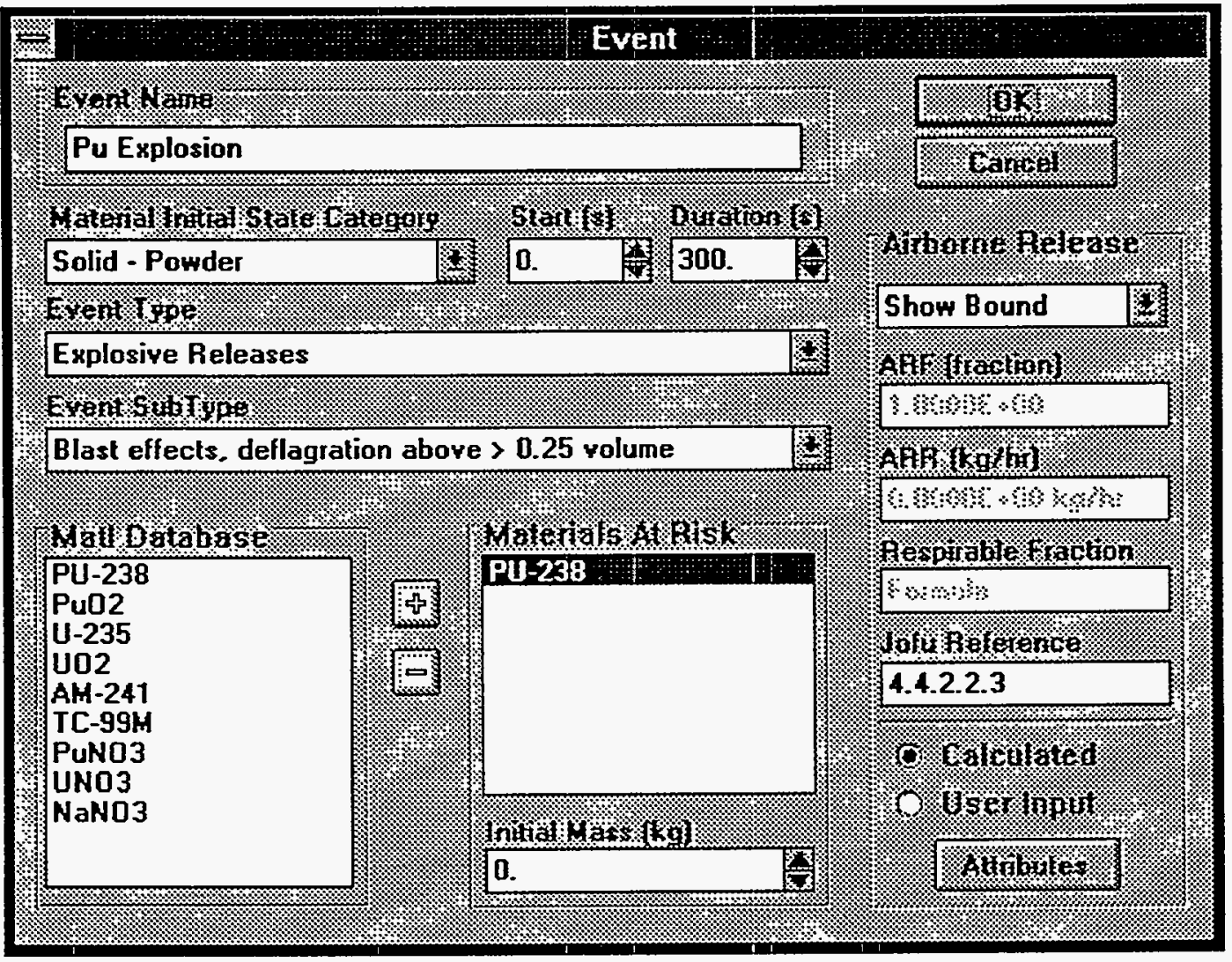

The controls in the Event dialog box which access the Mishima database are in the section labeled "Airborne Release" and are explained below:

ARF fraction The airborne release fraction, taken from the Mishima database, indicates the fraction of the material at risk that will be released when the event commences.

ARR The airborne release rate, taken from the Mishima database, indicates the rate at which the material at risk will be released into the surrounding air for the duration of the event. The duration is specified in the duration edit box explained in the following section, 4.3.2. 
Respirable

Fraction

Jofu Reference

Calculated/

User Input

Attributes
The respirable fraction, taken from the Mishima database, indicates the portion of the airborne material which is small enough to be inhaled deeply, i.e. $<10 \mu$.

The number given indicates the section of Jofu Mishima's draft report ${ }^{1}$ where the user could find documentation of the fractions used for the simulation.

Only one of these two buttons can be in effect at any given time. When "Calculated" has been chosen, this signifies that the values provided by the Mishima database will be used for the simulation. Also, the user may be required to supply some attributes so that the formulae can be evaluated in an accurate manner. When "User Input" is specified, this has two effects. First, any value which had the term "Formula" will be evaluated for the specific circumstances specified. Second, the user will be permitted to supply their own values for the three fractions. Material from the materials database can be added according to the rates of any user-defined scenario. Using this option, accidents are not restricted to those experimentally examined by Mishima[1993]'; however, caution must be exercised to specify defensible values since KBERT makes no sanity checks on the user specified values.

When "Calculated" has been specified, the user may be asked to supply some user selectable attributes that will be used in the formulation of the three values above (ARF, ARR, RF).

\subsubsection{Event attributes}

In the Event dialog box shown above, the controls which pertain to the event itself follow:

Event Name

Material Initial

State Category

Start

Duration

Event Type

Event Subtype

Matl Database
This edit box is used to give a unique name to the event.

This pull-down menu is used to select the appropriate initial state of the material at risk. The selection made here is used to provide appropriate choices in the Event Type list.

This edit box is used to specify the time at which the event will commence.

This edit box is used to specify the length of time that the event will continue to release the material at risk.

This pull-down menu allows the user to select the major type of event that caused the release of material. The selection made here is used to provide appropriate choices in the Event Subtype list below.

This pull-down menu allows the user to select the specific event based on the event type and initial state selected.

This list box shows all the materials which could be involved in the accident described by the material initial state and event type and subtype. 
Materials At Risk After the user selects a material from the Matl Database list box and uses the right arrow button, the material will become at risk during the simulated event and show up in this display box. Typically there will be only one material at risk; however, multiple materials can be selected and added to the list if the user so chooses.

Initial Mass The user may define the amount of material at risk that will be involved in the event during the simulation using this edit box. The up and down arrows on the right side of the edit box may be used to change the amount of initial material mass that is displayed in the box. If there are multiple materials at risk, then the initial mass will be for the material selected in the materials at risk list.

\subsubsection{Adding materials outside of events}

Materials can be manually added to the following facility objects: room atmospheres, structures, workers, and filters. The "Add" button of the Airborne Material section of the Edit Room dialog box allows addition of material directly into the room atmosphere. The "Materials" button of the Structures dialog box allows addition of settled material directly into the surface of the structure indicated. The structures typically include walls, floors and roofs chosen from the Settled Material/Material Location section of the Edit Room dialog box. Material may be deposited directly onto the skin of a worker by pressing the "Materials" button of the Worker dialog box. Material may be deposited directly onto a filter or flowpath by selecting the "Materials" button from either the Flowpath or Filter dialog box. Any of these actions will invoke the Materials dialog box described below:

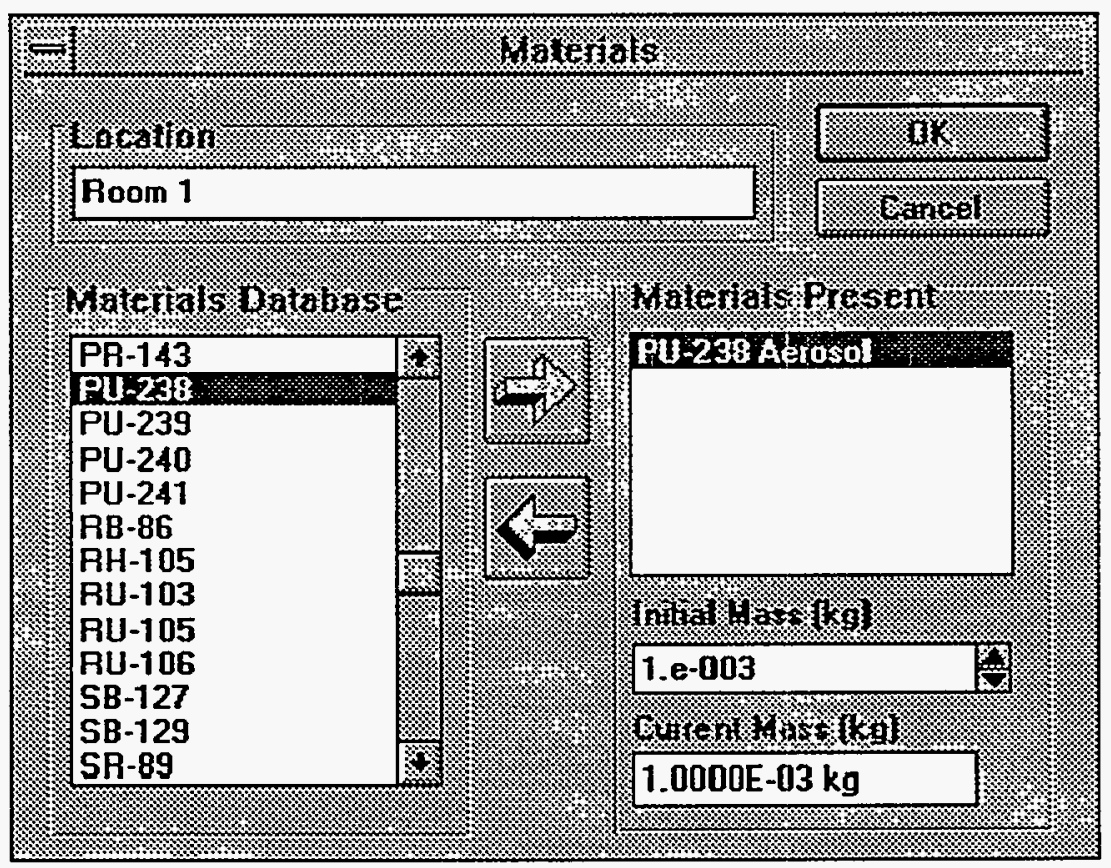

Location

Static box showing the location of the materials. The location cannot be changed; this is simply to remind the user where the material is being added. 
Materials Database List box showing all the materials available in the materials database. Any material from the database can be added by selecting it with the mouse and then pressing the "Add" button (see below).

Materials Present List box showing all the materials present in the facility at the location given in the Location edit box. The amount of each material is shown in the Initial Mass box when that material is highlighted.

Push button used to add the selected materials from the database to the location. If the material is being added to the room atmosphere a Pick Type dialog box is shown (see below) where the user must select to what extent the added material is respirable.

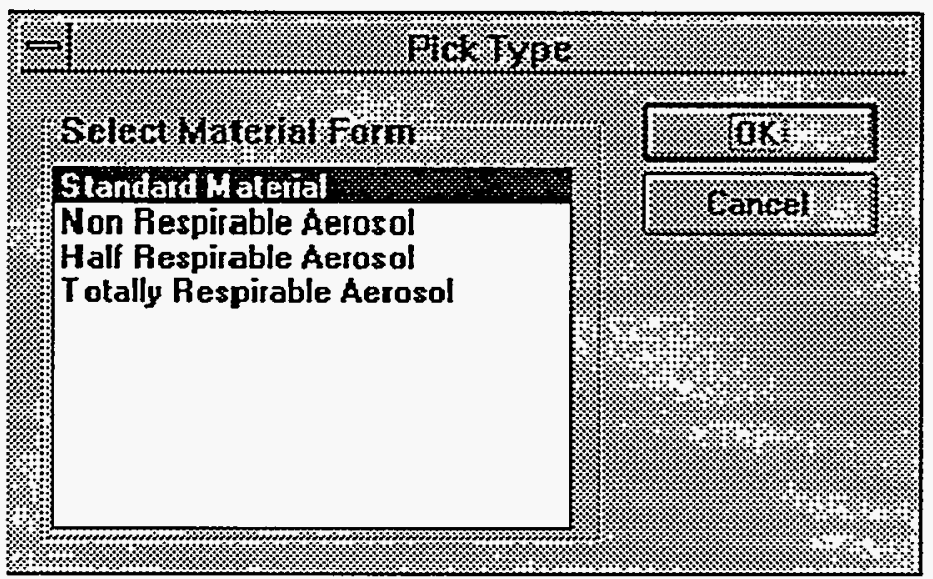

Standard Material will add the material as an airborne gas. If this type is selected the material will not be trapped by filters and it will not deposit by gravitational settling. If any of the other types are selected, the material will be added as an aerosol. The size of the aerosol will be governed by the formula given in the beginning of section 3.6, where RF is 0 for Non Respirable, 0.5 for Half Respirable, and 1.0 for Totally Respirable.

If the material is being added to any other location, this list is not shown since only airborne materials can be respirable.

Push button used to remove the materials selected in the Materials Present list box.

Initial Mass Edit box used to specify the initial mass of the material selected in the Materials Present list box.

Current Mass Static box showing the mass of the material selected in the Materials Present list box. At the start of a calculation this value will always equal the value in the Initial Mass box. After a calculation has begun, the amount remaining is shown. This might differ from the initial amount because of either aerosol transport (deposition) or because of radioactive decay. 


\subsection{Miscellaneous user options}

\subsubsection{Zoom in and out}

The "Zoom" functions are accessible from the center section of the View menu.

Zoom In This menu selection causes the rooms to enlarge by about $50 \%$. HVAC ducts remain the same size and hold their current screen coordinates. Filters also retain their original size. Ducts adjust their location to maintain the connection between their starting and ending rooms.

Zoom Out

This menu selection causes the rooms to reduce by about $50 \%$. Other facility elements react as they do when zooming in.

\subsubsection{Dots representing airborne material}

The number of dots used to represent the total airborne material in the facility can be set from the Value Input dialog box shown below. This screen can be accessed from the "Mass Dots" selection of the View menu.

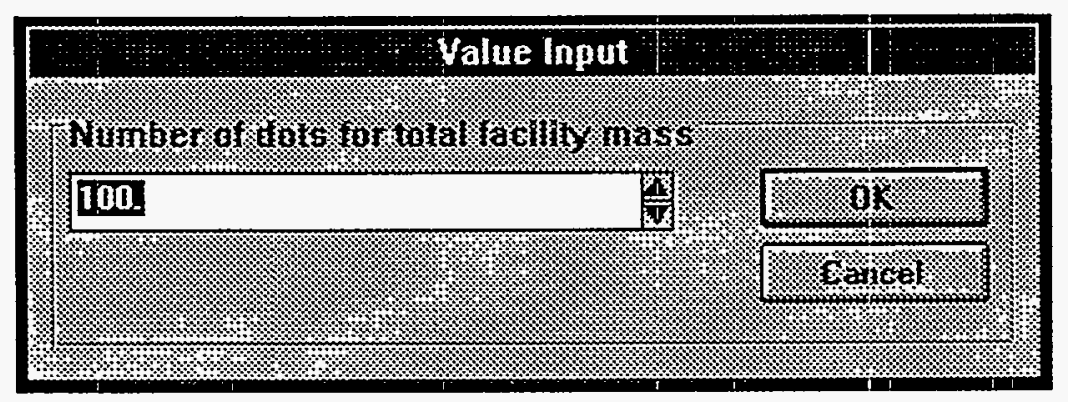

Number of dots

The number of dots that will visually represent the total mass of material at risk within a facility can be adjusted by either typing a new value into the edit box or by using the up and down arrows located at the right edge of the edit box. The larger the number specified, the greater the number of dots that will appear in any room which contains airborne material. The value also affects the number of dots shown representing material trapped in filters. 


\section{Running KBERT}

The previous chapters have described how to build facility models within the KBERT software. This chapter will describe how to run KBERT. To perform an analysis with KBERT one must specify an appropriate time step and accident duration. This is done from the Run Accident Simulation dialog box. The problem can then be run as a series of time steps or continuously. Most of the time users will perform analyses using the Run Accident Simulation dialog box; however, single steps can be taken while viewing the main KBERT screen. Section 5.1 describes the controls in the Run Accident Simulation dialog box, and Section 5.2 describes the options available for single stepping while viewing the main KBERT screen.

\subsection{Run Accident Simulation dialog box}

The time step used in KBERT must be specified in the Run Accident Simulation dialog box. This is true even if the single step analysis method is being used. This dialog box is invoked by selecting "Go" under the Run menu. The time step is changed simply by editing the value in the Time Step edit box. The simulation may then be run using the buttons in the upper right corner of the dialog box.

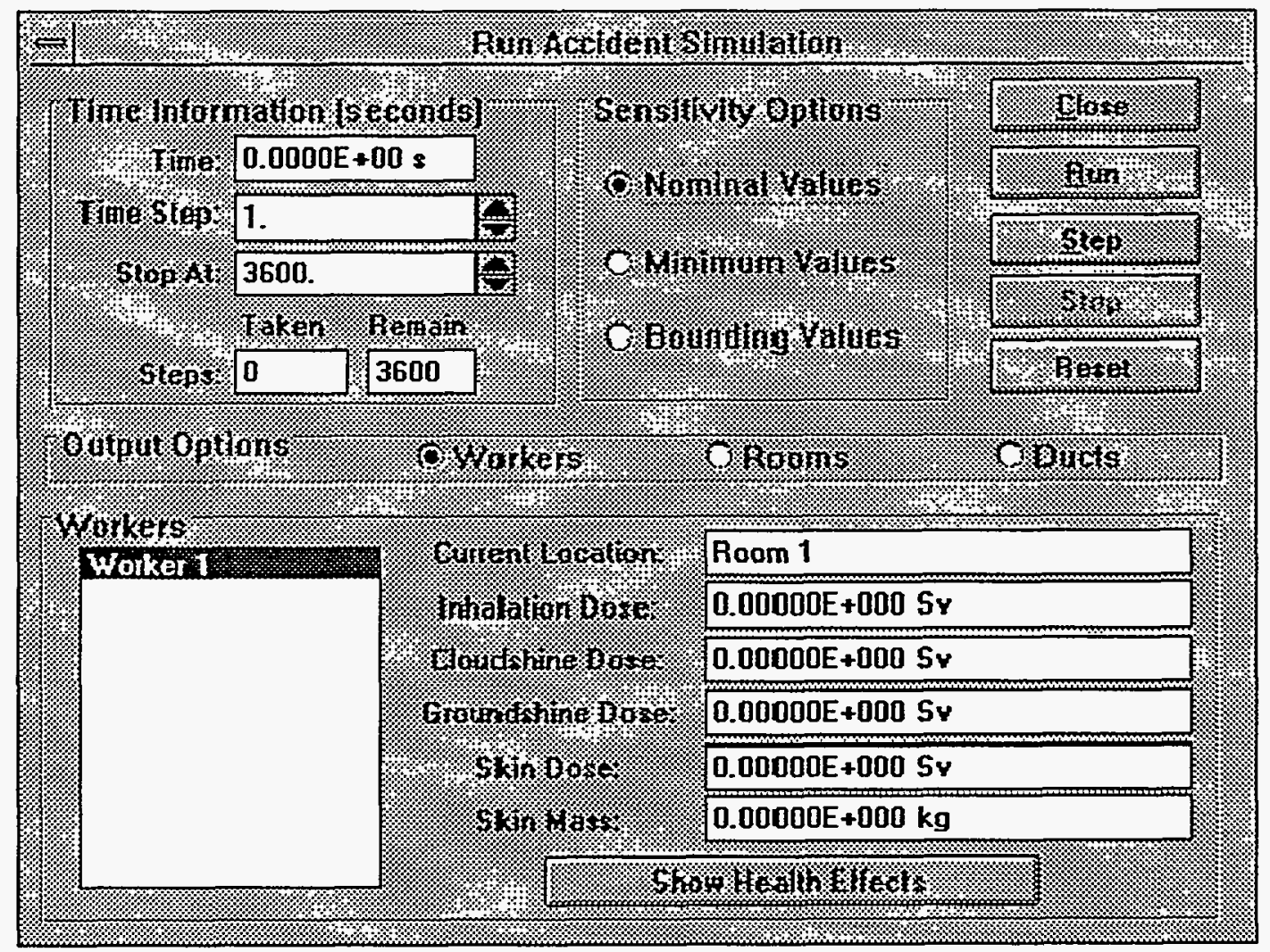

The time information and control boxes and the buttons that control running of the simulation are described below: 
Time

Time Step

Stop At

Steps Taken

Steps Remain

Run

Step

Stop

Reset

Sensitivity Options

This display-only box tells the user what time it is during the simulation. The simulation always starts at time zero and all times are displayed in seconds.

This edit box allows the user to view and modify the size of the steps, in seconds, that will be taken during the simulation. This determines the discrete steps at which the user may halt the simulation and examine the status of the facility elements.

This edit box allows the user to view and modify the time, in seconds, at which the simulation will halt. If the user wishes to continue the simulation when the stop time is reached, the stop time can be increased and the simulation resumed.

This display-only box tells the user how many steps have been taken at the current point in the simulation.

This display-only box tells the user how many steps remain to be taken at the current point in the simulation.

This button starts or resumes the simulation so that it runs unencumbered until the end time is reached or until the "Stop" button is clicked.

This button commences the simulation and advances the time by one step. This can be very useful for watching the status of rapidly changing facility elements.

This button pauses the simulation so that the status of the facility elements may be examined. A limited number of things can also be changed when the problem is stopped, including the time step and worker locations.

Most other parameters can only be changed when the problem is at time zero.

This button resets the simulation to time zero.

This group of buttons is used to identify which of the three release fraction options will be used in the analysis. In the Event dialog box a similar set of buttons is provided for viewing the three sets of ARF, ARR, and $R F$ values. In the Run Accident Simulation dialog box, the buttons are used to select which set to actually use.

\subsection{Single step analysis}

Users are encouraged to take a few single steps before running their problems continuously. The easiest way to do this is to press the "Step" button on the bottom of the Inspect bar while the main KBERT screen is showing. The screen will be updated to reflect the progression of time. The "Step" button can be pressed multiple times and the problem will continue to advance. After a few steps have been taken, the Run Accident Simulation dialog box can then be invoked so that a continuous run can be made. Single steps can also be taken from the Run Accident Simulation dialog box by pressing the "Step" button in the dialog box. This method is typically less desirable than using the Inspect bar or the Toolbar because the Run Accident Simulation dialog box covers most of the KBERT graphical screen view. This approach is desirable if you want to view 
precise quantitative information about a given room or worker as steps are taken. To do this select the room or worker of interest, then press "Step". The values in the Run Accident Simulation dialog box will be updated with the analysis results. 


\section{Viewing Output}

\subsection{Output in the Run Accident Simulation dialog box}

\subsubsection{Room output}

This screen can be accessed from the Run Accident Simulation dialog box by selecting the "Rooms" radio button under the Output Options section of the dialog box.

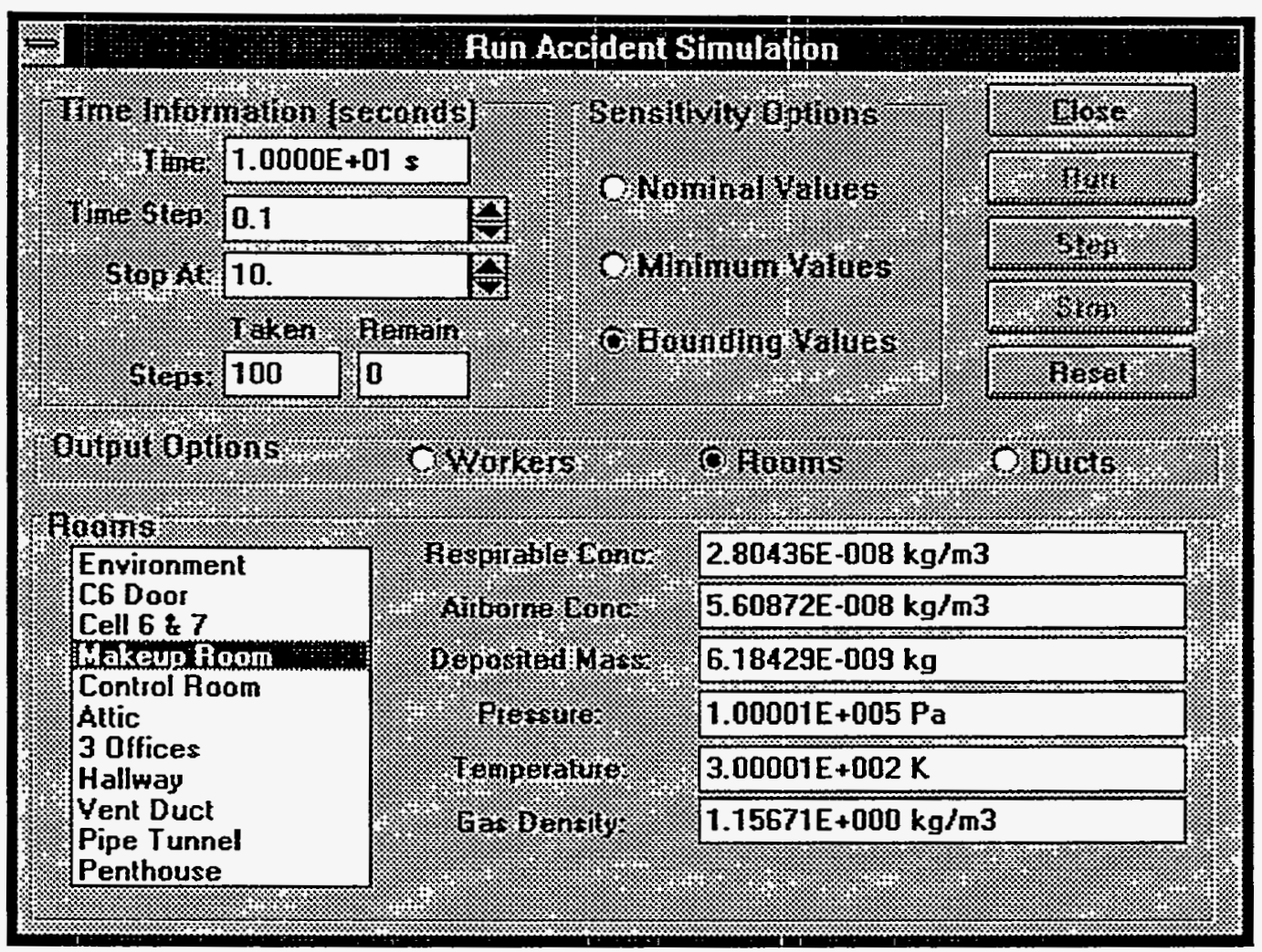

Each control and output display box for the Rooms view of the Run Accident Simulation dialog box is explained below:

Rooms This list box shows all the rooms in the facility. The blue bar indicates the currently selected room, which can be changed with a mouse click on the new room of choice. All the list boxes to the right of the rooms box display information about the room of choice.

Respirable Conc: This display-only list box shows the current respirable concentration of material at risk within the selected room. As the simulation progresses, this value will adjust as the conditions in the room change.

Airborne Conc: This display-only list box shows the current airborne concentration of material at risk within the selected room. If the particle size is large, there will typically be more airborne material than respirable material. 
Deposited Mass: This display-only list box shows the amount of deposited mass in the selected room. This value will include the mass deposited on any of the surfaces that the room contains.

Pressure: This display-only list box shows the current air pressure in the selected room.

Temperature: This display-only list box shows the current temperature in the selected room.

Gas Density: This display-only list box shows the density of the gas in the selected room.

\subsubsection{Worker output}

This screen can be accessed from the Run Accident Simulation dialog box by selecting the "Workers" radio button under the Output Options section of the dialog box.

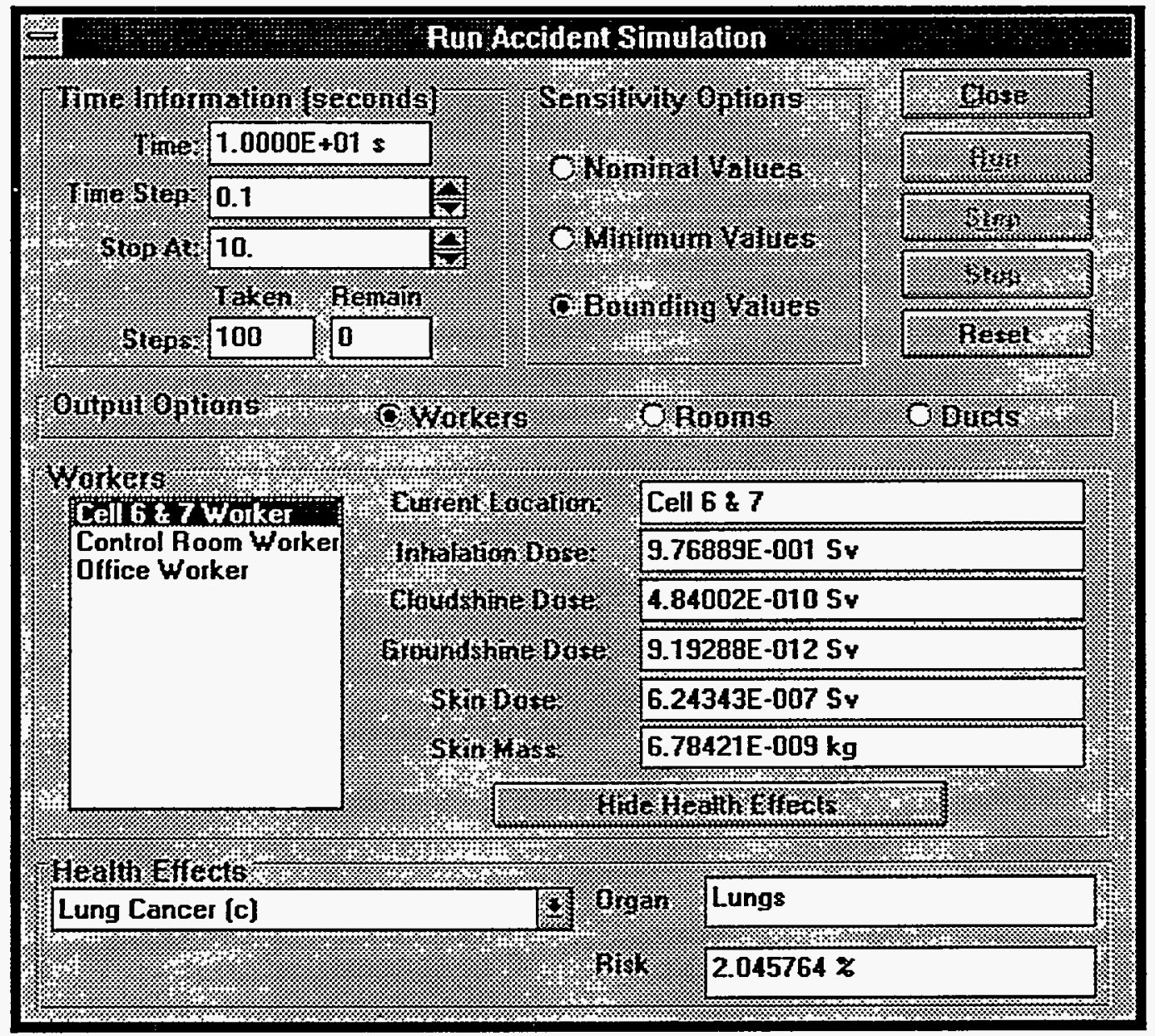

\subsubsection{Dose results}

Each control and output display box for the dose results section of the Workers view of the Run Accident Simulation dialog box is explained below: 
Workers

Current Location

Inhalation Dose

Cloudshine Dose

Groundshine Dose

Skin Dose

Skin Mass
This list box shows all the workers or worker groups in the facility. The blue bar indicates the currently selected worker(s), which can be changed with a mouse click on the new worker(s) of choice. All the list boxes to the right of the Workers box display information about the worker(s) of choice.

This display-only list box shows the name of the room where the selected worker(s) is located at the current time in the simulation.

This display-only list box shows the total inhalation dose received thus far by the selected worker. If a group of workers is involved, each worker will have received the dose displayed.

This display-only list box shows the total cloudshine dose received thus far by the selected worker(s).

This display-only list box shows the total groundshine dose received thus far by the selected worker(s).

This display-only list box shows the total skin dose received thus far by the selected worker(s).

This display-only list box shows the total mass of material deposited on the skin of the selected worker(s) thus far in the simulation.

\subsubsection{Health effects}

Each control and output display box for the health effects section of the Workers view of the Run Accident Simulation dialog box is explained below. This section of the dialog box becomes visible when the "Show Health Effects" button is pushed. It can be removed by pushing the "Hide Health Effects" button.

Health Effects The health effects fall into three categories: d, i and c. This indicates the probable consequences that would result from this health effect:

$$
\begin{array}{lll}
\mathrm{d} & - & \text { death } \\
\mathrm{i} & - & \text { injury } \\
\mathrm{c} & - & \text { latent cancer }
\end{array}
$$

The health effects included in KBERT thus far include only those known to result from radiological exposure. For more information on dose and health effect determination, the reader is referred to Monroe's [1994] $]^{3}$ assessment.

Organ This display box shows the major organ that is affected by the health effect currently selected.

Risk This display box shows the risk factor for the health effect currently selected. For a reading of $10 \%$, this would indicate that if 100 people were exposed to the conditions of the simulation, it is estimated that the dose level would be expected to induce the specified health effect in ten people. The estimate is derived from existing field or clinical data. 


\subsubsection{Flowpath output}

This screen can be accessed from the Run Accident Simulation dialog box by selecting the "Ducts" radio button under the Output Options section of the dialog box.

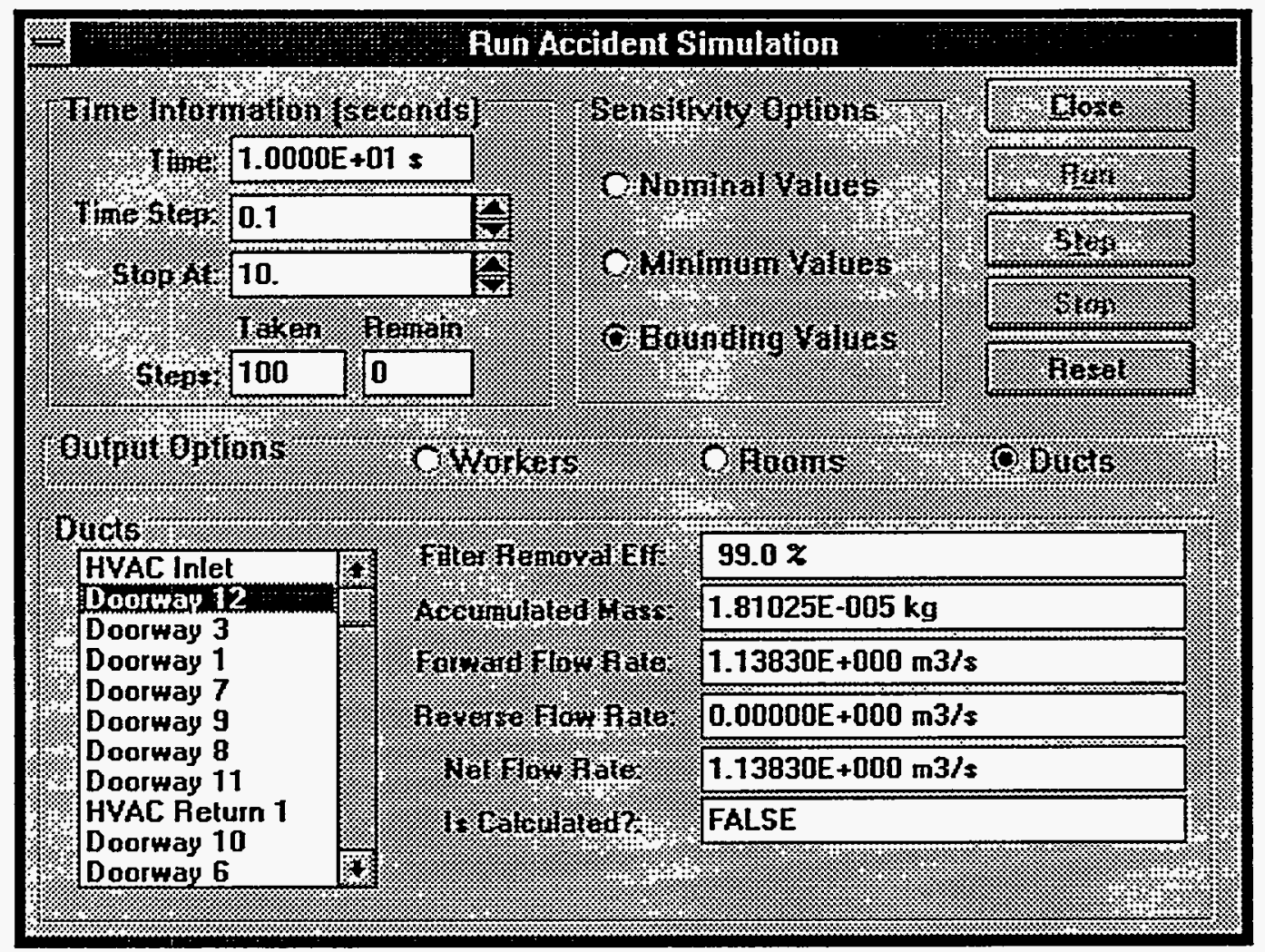

Each control and output display box for the Ducts view of the Run Accident Simulation dialog box is explained below:

Ducts

This list box shows all the flowpaths in the facility. The blue bar indicates the currently selected flowpath, which can be changed with a mouse click on the new flowpath of choice. All the list boxes to the right of the Ducts box display information about the flowpath of choice.

Filter Removal Eff It is possible to have a filter on any flowpath in a KBERT facility. This display-only list box shows the removal efficiency of the filter for the selected flowpath. If there is no filter on the chosen flowpath, the removal efficiency will be zero.

Accumulated Mass This display-only list box shows the mass of the material that has accumulated thus far on the filter in the selected flowpath. If no filter exists on this flowpath, the accumulated mass will be zero. Mass is not allowed to settle in an unfiltered flowpath.

Forward Flow Rate This display-only list box shows the rate of flow through the flowpath in the positive direction (as defined at creation) at the current time in the simulation. This flow rate will be updated as the simulation progresses. 
Reverse Flow Rate This display-only list box shows the rate of flow through the flowpath in the reverse direction (as defined at creation) at the current time in the simulation. This flow rate will be updated as the simulation progresses. Air may be flowing in both directions through a flowpath at any given time.

Net Flow Rate This display-only list box shows the net rate of flow through the flowpath of choice at the current time in the simulation. The value will be positive if the net flow is in the positive direction (as defined at creation) and will be negative if the net flow is in the negative direction.

Is Calculated? This display-only list box can be either true or false:

True: The flow rate is calculated based on the flow rates in the rest of the facility. This is specified by the user from the Flowpath dialog box by clicking on the "Check here to calculate the flow rates" option.

False: The flow rate is specified at all times by user input. This can be done using the "Flow Profile" button from the Flowpath dialog box or by specifying the forward and reverse flow rates from the Flowpath dialog box.

\subsection{Visual feedback in the facility view}

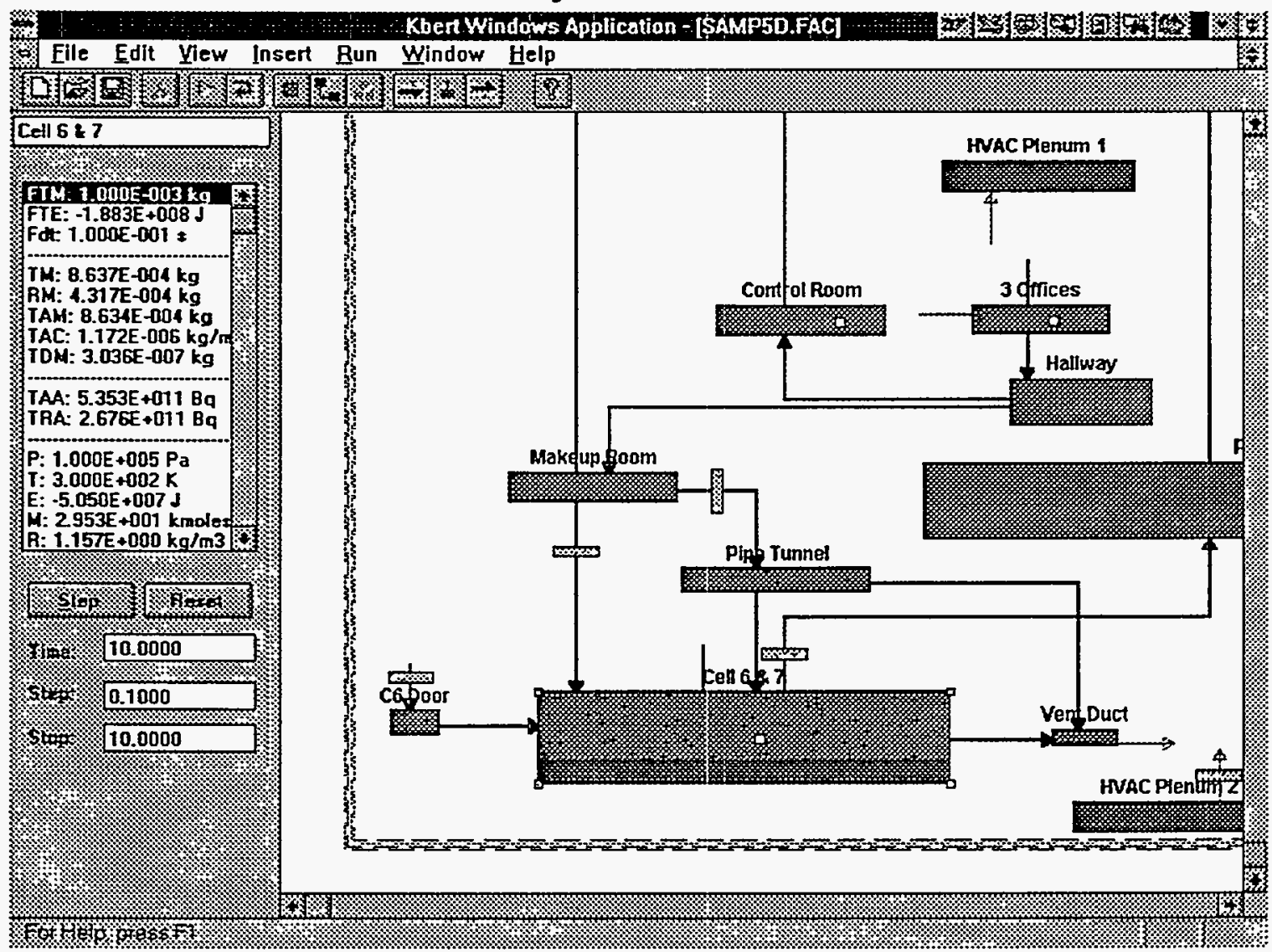


A rough visual estimate of the flow of contaminant through the facility can be attained from the facility view as shown above. The contaminant can be seen in the form of black dots which appear mostly in Cell $6 \& 7$, the room where the event has occurred. The contaminant has spread to the Vent Duct room, the Pipe Tunnel, the Makeup Room, the C6Door, and several filters. In reality, the contaminant is also present in the other rooms but the concentration is too low to be visible from the facility view. The controls are described below:

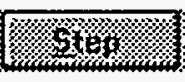

\section{f $3=2$}

mato

The step button can be used to step through the simulation while in the facility view. This allows the user to watch the material spread through the facility in the form of black dots that initially appear in the room with the red bar where the event occurs, then spread throughout the facility and deposit on filters. The dots disappear from the screen as the material settles onto surfaces. The total number of dots can be set from the View menu via the "Mass Dots" option.

The reset button allows the user to reset the simulation.

These two buttons perform the same functions as the "Step" and "Reset" buttons of the inspect bar.

Time, Step \& Stop These display-only edit boxes on the inspect bar shows the current status of the simulation. Time shows the current time, Step shows the amount of time that a step will advance and Stop shows the time at which the simulation will halt.

\subsection{Using the inspect bar}

The inspect bar gives the user detailed information about the selected facility element in the facility view. Different information is displayed depending upon the type of facility element that is selected. The three types of elements and the values available are presented below:

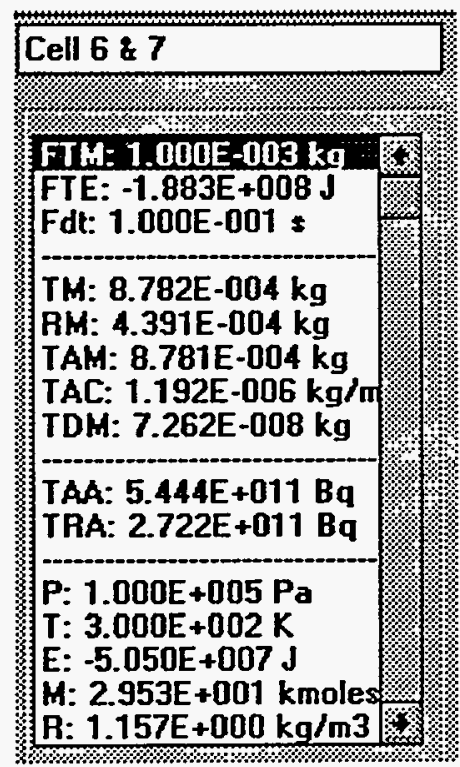

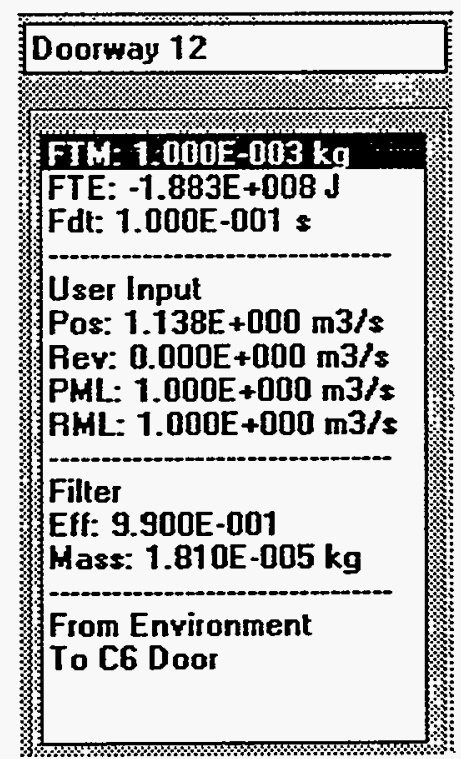

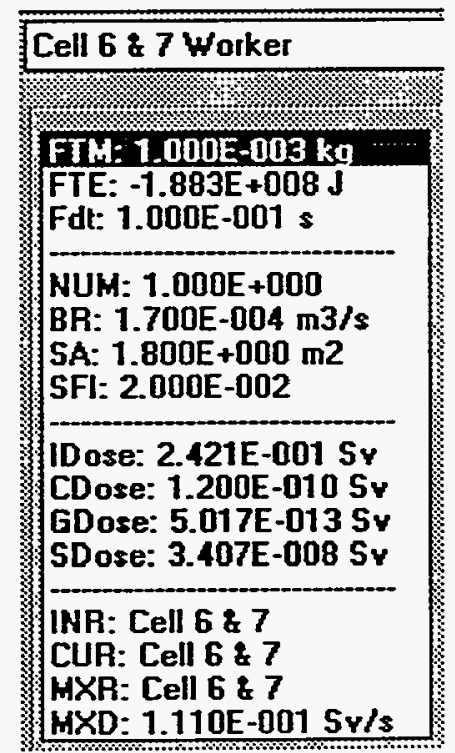


The values shown above in the three views of the inspect bar represent the following:

Room View

Flowpath View

Worker View
Facility Total Mass, Facility Total Energy, Facility Time Step, Total Mass, Respirable Mass, Total Airborne Mass, Total Airborne Concentration, Total Deposited Mass, Total Airborne Activity, Total Respirable Activity, Pressure, Temperature, Energy, Gas Density.

Facility Total Mass, Facility Total Energy, Facility Time Step, Positive Flow Rate, Reverse Flow Rate, Positive Flow Multiplier, Reverse Flow Multiplier, Filter Removal Efficiency, Filter Accumulated Mass, Direction of Positive Flow.

Facility Total Mass, Facility Total Energy, Facility Time Step, Number of Workers in the Workgroup, Breath Rate, Skin Area, Inhalation Shielding Factor, Inhalation Dose, Cloudshine Dose, Groundshine Dose, Skin Dose, Initial Room, Current Location, Room where maximum dose was received, Maximum Dose Received in any single timestep.

\section{Summary}

This manual gives detailed instructions on how a user who is familiar with the design, layout and potential hazards of a facility can use KBERT to assess the possible consequences to workers in that facility. KBERT is a tool that allows a user to simulate possible accidents and observe the predicted consequences. Potential applications of KBERT include the evaluation of the efficacy of evacuation practices, worker shielding, personal protection equipment and the containment of hazardous materials. 


\section{Appendix A}

\section{References}

1. J. Mishima, "Recommended Values and Technical Bases for Airborne Release Fractions (ARFs), Airborne Release Rates (ARRs) and Respirable Fractions for Materials from Accidents in DOE Fuel Cycle, Ex-Reactor Facilities," Draft Revision 2, April 1993.

2. T. Heames and J. Brockmann, "Aerosol Deposition in Leak Paths," Draft Revision 1, Sandia National Laboratories, Albuquerque, NM, June 1994.

3. D. Monroe, "Calculation of Doses and Consequences for KBERT," Draft Revision 1, Sandia National Laboratories, Albuquerque, NM, June 1994.

4. American Conference of Governmental Industrial Hygienists: Particle Size - Selective Sampling in the Workplace, ACGIH, Cincinnati, OH (1985).

5. K. Washington, et. al., "Reference Manual for the CONTAIN 1.1 Code for Containment Severe Accident Analysis," NUREG/CR-5715, SAND91-0835, Sandia National Laboratories, Albuquerque, NM, July 1991.

6. International Commission on Radiological Protection (ICRP) Publication 26.

Recommendations of the ICRP. Annals of the ICRP 1(3) (1977). Reprinted (with additions) in 1987. Superseded by ICRP Publication 60. 


\section{Distribution}

4

Dr. Subir K. Sen, P. E.

EH-34 GTN, Rm. D430

U. S. Department of Energy

19901 Germantown Road

Germantown, MD 20874-1290

1 Andrew Marchese

EH-34 GTN

U. S. Department of Energy

19901 Germantown Road

Germantown, MD 20874-1290

1 J. La Chance

SAIC - Albuquerque

2109 Air Park Rd, S.E.

Albuquerque, NM 87106

$1 \quad$ M. Butner

MS K557

LANL

Los Alamos, NM 87545

1 S. Fischer

ORNL

P.O. Box 2009

Oak Ridge, TN 37831
$1 \quad$ Calvin Lai

U. S. Department of Energy

Mail Stop GTN EH 3.4.1

19901 Germantown Road

Germantown, MD 20874-1290

$1 \quad$ William Arcieri

Scientech, Inc.

11821 ParkLawn Drive

Rockville, MD 20852

$1 \quad$ P. K. Mast

ITS

8015 Mt. Rd Place, NE

Suite 210

Albuquerque, NM 87110

1 Patrick McClure

MS K557

LANL

Los Alamos, NM 87545
2 MS0100

$1 \quad$ MS0619

$1 \quad$ MS0718

$1 \quad \mathrm{MS0722}$

10 MS0722

$1 \quad$ MS0722

$1 \quad$ MS0744

$1 \quad$ MS0748

$5 \quad$ MS0899

$1 \quad$ MS1037

$1 \quad$ MS1137

$1 \quad$ MS1175

1 MS1305

$1 \quad$ MS 9018
Document Processing, 7613-2 For DOE/OSTI

Print Media, 12615

E. A. Kjeldgaard, 6641

K. E. Washington, 6913

D. S. Browitt, 6913

J. M. Linebarger, 6913

D. A. Powers, 6404

D. K. Monroe, 6413

Technical Library, 13414

K. E. Kern, 7258

T. J. Heames, 6422

L. A. Miller, 6513

D. S. Campbell, 7576

Central Technical Files, 8523-2 